\title{
Insights into Disease-Associated Tau Impact on Mitochondria
}

\author{
Leonora Szabo 1,2, Anne Eckert 1,2 and Amandine Grimm 1,2,3,* \\ 1 Neurobiology Lab for Brain Aging and Mental Health, Transfaculty Research Platform, \\ Molecular \& Cognitive Neuroscience, University of Basel, 4002 Basel, Switzerland; \\ leonora.szabo@unibas.ch (L.S.); anne.eckert@unibas.ch (A.E.) \\ 2 Psychiatric University Clinics Basel, 4002 Basel, Switzerland \\ 3 Live Sciences Training Facility, Division of Molecular Psychology, University of Basel, \\ 4055 Basel, Switzerland \\ * Correspondence: amandine.grimm@unibas.ch; Tel.: +41-61-325-5347; Fax: +41-(0)-61325-55-77
}

Received: 9 July 2020; Accepted: 28 August 2020; Published: 1 September 2020

\begin{abstract}
Abnormal tau protein aggregation in the brain is a hallmark of tauopathies, such as frontotemporal lobar degeneration and Alzheimer's disease. Substantial evidence has been linking tau to neurodegeneration, but the underlying mechanisms have yet to be clearly identified. Mitochondria are paramount organelles in neurons, as they provide the main source of energy (adenosine triphosphate) to these highly energetic cells. Mitochondrial dysfunction was identified as an early event of neurodegenerative diseases occurring even before the cognitive deficits. Tau protein was shown to interact with mitochondrial proteins and to impair mitochondrial bioenergetics and dynamics, leading to neurotoxicity. In this review, we discuss in detail the different impacts of disease-associated tau protein on mitochondrial functions, including mitochondrial transport, network dynamics, mitophagy and bioenergetics. We also give new insights about the effects of abnormal tau protein on mitochondrial neurosteroidogenesis, as well as on the endoplasmic reticulum-mitochondria coupling. A better understanding of the pathomechanisms of abnormal tau-induced mitochondrial failure may help to identify new targets for therapeutic interventions.
\end{abstract}

Keywords: tau protein; mitochondria; tauopathies

\section{Introduction}

The brain is a high-energy consuming organ and requires a remarkable $20 \%$ of the body's energy to fulfill its functions. In order to meet this high energy demand, neuronal cells strongly rely on the proper performance of the oxidative phosphorylation system (OXPHOS) of mitochondria [1]. Accordingly, the maintenance of proper mitochondrial function is of utmost importance for functional energy production and consequently the viability of neurons [2]. Thus, long-lasting disturbances may induce various pathologies, ranging from subtle alterations in neuronal function to cell death and neurodegeneration [1]. Therefore, mitochondrial dysfunction seems to be a hallmark of neurodegenerative disorders, such as Alzheimer's disease (AD), Parkinson's disease (PD) and Huntington's disease (HD), and was observed already at early disease stages, before the onset of cognitive impairments [3,4].

Tau protein belongs to the family of microtubule-associated proteins (MAPs) that stabilize microtubule assembly and function (reviewed in [5]). Tau is expressed in most neurons and plays a role in axonal transport, cell polarity, and neurotransmission. Tau is also involved in the pathophysiology of neurodegenerative disorders called tauopathies that are characterized by an aberrant intracellular accumulation of tau within neurons, abnormal tau hyperphosphorylation and assembly into neurofibrillary tangles (NFTs). In primary tauopathies, such as frontotemporal lobar 
degeneration (FTLD), Pick's disease, corticobasal degeneration (CBD), progressive supranuclear palsy (PSP), and sporadic multiple system tauopathy, tau plays a primary role and mutant forms of tau proteins were identified [5]. In secondary tauopathies, such as AD, Creutzfeldt-Jakob disease and Chronic Traumatic Encephalopathy (CTE), tau plays also a role in the pathogenesis of the disease but other major factors are involved, as, for instance, amyloid- $\beta(A \beta)$ accumulation in AD. Substantial evidence has been linking abnormal tau to neurodegeneration, but the mechanisms underlying tau-induced neuronal dysfunction and death are still incompletely understood.

Mounting evidence highlights the dysfunction of mitochondria in tauopathies, including reduced bioenergetics as well as abnormal mitochondrial morphology [6,7]. Besides, abnormal tau has many effects on other cellular functions that may lead to neurodegeneration, which are nicely reviewed elsewhere [8-10]. In the present review, we aim to give insights about tau impacts on the different functions of mitochondria in order to draw a "mitocentric" picture of tau toxicity. First, we summarize what is known about tau protein structure and function in health and disease. Then, we remind important aspects of mitochondrial function in order to better apprehend the impact of tau on this paramount organelle. Finally, we discuss how disease-associated tau disturbs mitochondrial functions, including recent developments from the past five years, as well as new insights about abnormal tau effects on mitochondrial neurosteroidogenesis and the endoplasmic reticulum (ER)-mitochondria coupling.

\section{Tau Protein}

\subsection{Tau Structure and Domains}

In the human genome, tau proteins are encoded by a single gene, the microtubule-associated protein tau (MAPT) gene, which comprises 16 exons located on chromosome 17q21 [5,11-14]. Alternative splicing of exons 2, 3 and 10 results in the expression of six different isoforms $(2 \mathrm{~N} 4 \mathrm{R}, 1 \mathrm{~N} 4 \mathrm{R}, 0 \mathrm{~N} 4 \mathrm{R}$, $2 \mathrm{~N} 3 \mathrm{R}, 1 \mathrm{~N} 3 \mathrm{R}, 0 \mathrm{~N} 3 \mathrm{R})$ that are all present in the adult human brain. These splicing variants differ from each other in the presence of zero, one or two $\mathrm{N}$-terminal inserts $(0 \mathrm{~N}, 1 \mathrm{~N}$ or $2 \mathrm{~N}$, respectively) and in the number of either three (3R) or four (4R) microtubule-binding repeats in the C-terminal part $[10,11,13,15]$. While the six isoforms appear to be broadly functionally similar, each is likely to have specific and partially distinctive physiological roles. Of particular interest are the splicing products of exon 10, the $3 \mathrm{R}$ and $4 \mathrm{R}$ isoforms, normally being expressed in a one-to-one ratio in most regions of mature brains $[16,17]$. However, deviations from this ratio are associated with certain tauopathies, which can be classified into three groups $(3 R, 4 R$ or $3 R / 4 R$ ) depending on the isoforms found in pathogenic aggregates, and thereby facilitating the onset of the disease [18]. Specifically, compared to $3 R$ tau, $4 \mathrm{R}$ tau exhibits a higher affinity for microtubules, and is consequently more efficient in promoting microtubule assembly $[10,19]$. Interestingly, the two isoforms also seem to impact the motor function of microtubules differentially. Whereas $4 \mathrm{R}$ tau decreases the localization of mitochondria to axons to a greater extent than $3 R$ tau, the $3 R$ isoforms are more efficient in increasing the percent of mitochondria moving in the retrograde direction $[5,20]$. Besides, depending on the isoform tau contains either one or two cysteine residues in the microtubule-binding domain. While in the 3R isoform only C322 within the third repeat is present, 4R tau additionally comprises C291 within the fourth repeat. This variance seems to have an influence on the assembly of paired helical filaments (PHFs) in vitro [21].

The structural basis of tau to bind its interaction partners and to perform its functions lies in the organization of tau's amino acid sequence. Depending on the biochemical properties, tau can be subdivided into the N-terminal projection domain, the proline-rich region, the microtubule-binding domain and the C-terminal region [22-24]. When bound to microtubules, the $\mathrm{N}$-terminal domain of tau projects away from the microtubule surface, where it is believed to interact with components of the neuronal plasma membrane $[25,26]$. Moreover, this region is involved in determining the spacing between microtubules $[11,22,27]$. The proline-rich region instead harbors PXXP motifs that provide potential recognition sites for $\mathrm{SH} 3$ domain-containing proteins of the Src family kinases, 
such as Fyn, playing a role in signal transduction [22,26,28]. Furthermore, the ability of tau to interact with microtubules is mediated by the microtubule-binding domain in combination with the adjacent proline-rich flanking domains. Whereas the microtubule-binding repeats bind only weakly to microtubules (but possess specificity for microtubule assembly), the proline-rich region provides an efficient targeting to the microtubule surface $[29,30]$.

Tau is a highly soluble, natively unfolded protein that maintains a highly flexible conformation and overall has little secondary structure [31]. However, when binding to interacting proteins and partners, tau may form local conformations [29]. Furthermore, it has been proposed that soluble tau preferentially changes its global conformation to a paperclip structure, where the C-terminal region folds over the microtubule-binding domain and the $\mathrm{N}$-terminal region folds back over of the C-terminal one, placing them in close proximity [32]. This paperclip fold formation might protect tau from aggregation [33]. Truncated tau has a higher tendency for aggregation [34], which could be probably due to the disruption of the paperclip structure [33].

\subsection{Post-Translational Modifications}

Besides alternative splicing, tau is a subject of numerous post-translational modifications that highly regulate the functions of tau in both physiological and pathological conditions. The most commonly described post-translational modification of tau is phosphorylation. Tau is a phosphoprotein containing 85 potential phosphorylation sites on the longest tau isoform consisting of 45 serine, 35 threonine and 5 tyrosine residues $[5,35,36]$. Tau phosphorylation is developmentally regulated with fetal tau experiencing higher levels of modification than adult tau [37]. The normal phosphorylation state of tau is a consequence of the dynamic regulation between the activities of a large number of protein kinases and phosphatases [22,38]. Many different kinases have been demonstrated to be involved in the site-specific phosphorylation of tau. Tau phosphorylating kinases include, among others, the glycogen synthase kinase (GSK) $3 \alpha / \beta$, cyclin-dependent kinase 5 (Cdk5), mitogen-activated protein kinases (MAPKs), tau-tubulin kinase 1/2 (TTBK1/2), cAMP-dependent protein kinase A (PKA), protein kinase $\mathrm{C}(\mathrm{PKC}), 5^{\prime}$ adenosine monophosphate-activated protein kinase (AMPK), calcium/ calmodulin-dependent protein kinase II (CaMKII), and finally tyrosine kinases of the Src family like Src, and Fyn [39]. Of those, GSK $3 \beta$ and Cdk5 are especially supposed to play a relevant role in the pathogenesis of tauopathies like $\mathrm{AD}$, contributing to increased phosphorylation [23,40]. Conversely, several protein phosphatases including protein phosphatase 1 (PP1), PP2A, PP2B, PP2C and PP5 have been implicated in tau de-phosphorylation [38]. Among them PP2 is considered as the main phosphatase, accounting for approximately $70 \%$ of the total tau phosphatase activity in the brain. Moreover, it was demonstrated that PP2 activity is 50\% decreased in AD brains, thus leading to increased phosphorylation of tau [41]. While tau phosphorylation traditionally has been the most intensively studied post-translational tau modification, tau is likewise a target of many other post-translational modifications, including acetylation, glycosylation, glycation, deamidation, prolyl-isomerisation, nitration, sumoylation, methylation, ubiquitination, and truncation (reviewed in $[5,22])$. Together, these modifications differentially regulate the functions of tau and may as well influence one another. Nevertheless, in contrast to the more investigated role of phosphorylation in tau pathology, the implication of the other tau post-translational modifications is yet to be fully characterized.

\subsection{Physiological Functions of Tau}

Tau is considered as a multi-functional protein that plays a number of different roles in neuronal cells. In the adult human brain, tau is predominantly distributed in the axons of neurons [11,42]. There, one of tau's primary functions is to bind microtubules, where this interaction promotes microtubule assembly and thereby modulates their stability $[5,43]$. Remarkably, physiologically more than $90 \%$ of tau is attached to microtubules [44]. This ability of tau to bind microtubules is mediated by KXGS motifs within the microtubule-binding domain and proline-rich flanking domains $[45,46]$. While microtubule-binding repeats attach to the inner face, the flanking regions interact with the 
surface of microtubules [47]. Under physiological conditions, binding of tau to microtubules is a highly dynamic process that is dependent on several factors, including tau isoforms, mutations, post-translational modifications, but also the method used to determine the interaction between tau and microtubules [23]. Concerning the influence of post-translational modifications, this binding ability is most prominently regulated by tau's phosphorylation state [35,48]. Kinase-mediated phosphorylation of tau detaches the protein from microtubules and subsequently causes their depolymerization, whereas phosphatases de-phosphorylate tau and retain the binding ability to microtubules [49]. Especially the phosphorylation of the KXGS motifs within the microtubule-binding domain has been shown to strongly reduce the binding ability of tau to microtubules [36,50]. Frequent cycles of binding and detachment of tau from microtubules are not only important for the regulation of microtubule stability, but consequently affect the maintenance of effective axonal transport [36]. Axonal transport is a critical process in neurons required for the efficient movement of organelles, lipids, proteins, nucleic acids, and synaptic vesicles. Microtubules provide the platforms for proper intracellular transport by allowing motor proteins to interact with them [51]. While kinesins transport cargoes in the anterograde direction, dyneins are carrying cargoes in the retrograde direction [52]. Upon microtubule binding, tau is involved in the regulation of axonal transport, where tau modulates the motility of kinesin and dynein. When encountering microtubule-bound tau dynein tends to reverse direction, whereas kinesin detaches at patches of bound tau in a concentration- and isoform-dependent manner [53]. Moreover, tau binds to the p150 subunit of dynactin, which stabilizes the interaction of dynein with microtubules, and thus supports dynein-dependent axonal transport [54]. Since axonal transport of cargoes, like mitochondria, to different parts of neurons is essential for a proper synaptic function, pathological changes of tau may lead to the impairment of this transport [55]. In addition to these well-known functions, tau was also found to interact with the actin cytoskeleton. Tau protein may bind to filamentous actin to induce aligned bundles of actin filaments, therefore modifying the organization of the cytoskeleton network $[5,56]$. To note, physiologically a small amount of tau distributes as well in dendrites. However, the physiological function of dendritic tau has not been well elucidated. Nonetheless, it has been proposed that tau has a dendritic role in the post-synaptic targeting of the Fyn kinase [57,58], where it binds Fyn through PXXP motifs within its proline-rich region and thus promotes the recruitment of Fyn to NMDA receptors [58,59]. The targeting of tau to the post-synapse may play a role in mediating synaptic plasticity, especially long-term depression [60] and hence memory formation [61]. Besides, in axons and dendrites, tau has additionally been detected in the nucleus. Nuclear tau appears to be involved in protecting the integrity of genomic DNA, nuclear RNA and cytoplasmic RNA, thus ensuring their functionality and longevity [62-64].

\subsection{Pathological Aggregation of Tau}

Under pathological conditions, alterations in the properties of tau may lead to its aggregation that is characteristic of several neurodegenerative diseases. The conversion of physiologic soluble tau species into pathologic fibrillary tau aggregates is considered to be a multi-step process [11]. As one of the mechanisms to drive tau aggregation aberrant phosphorylation has been assumed, since hyperphosphorylation and aggregation of tau are both increased in AD [65]. Hyperphosphorylation of tau is most likely to result from an imbalance in the activities of specific tau kinases and phosphatases, causing an increased rate of tau phosphorylation and/ or decreased rate of de-phosphorylation [66]. Consequently, tau hyperphosphorylation reduces its binding affinity to microtubules, thereby induces a loss of tau's normal microtubule-stabilizing function [67,68], and thus causes microtubule depolymerization [49]. Specifically, the phosphorylation of KXGS motifs within the microtubule-binding domain (in particular S262) and S214 within the flanking region of tau have been described to strongly decrease the affinity of tau for microtubules $[69,70]$. Furthermore, in vitro studies demonstrated that phosphorylation of T231 within the flanking region also contributes to the reduced binding of tau to microtubules [71]. The detachment of tau from microtubules subsequently leads to an abnormal increase of free unbound tau in the cytosol [72]. This higher cytosolic concentration 
may render tau substantially more likely to undergo misfolding. Thereafter, as an early pathological event, non-fibrillar tau deposits, referred to as pre-tangles, are formed. Following steps comprise conformational changes leading to the generation of PHFs. This transition from pre-tangles to PHFs includes the formation of characteristic $\beta$-sheet-like structures [11,73]. Precisely, the hexapeptide motifs PHF6 and PHF6* located in the second and third microtubule-binding repeats exhibit a high $\beta$-sheet propensity, and are supposed to promote abnormal tau aggregation in vitro and in cell and animal models $[22,23,26]$. Finally, PHFs further self-assemble to form more organized aggregates, and eventually develop insoluble NFTs inside neurons. The following sequestration of NFTs together with compromised cytoskeleton dynamics impairs normal axonal transport, and hence contributes to synaptic dysfunction and neurodegeneration [74,75]. In addition, alterations of tau itself, such as mutations in the MAPT gene, can also contribute to tau aggregation. For instance, in the tau mutations P301L, P301S and $\triangle \mathrm{K} 280$ that are found in frontotemporal dementia with parkinsonism-17 (FTDP-17) the hexapeptide motif $\mathrm{PHF}^{*}$ is present. As a result of this enhanced $\beta$-sheet propensity, tau with these mutations tends to have a decreased affinity for microtubules and an increased ability to assemble into filaments, thus promoting tau aggregation $[22,30,76]$. To point out, even though phosphorylation of S262 and S214 strongly prevents the attachment of tau to microtubules, phosphorylation of these sites tends to inhibit PHF formation [21].

Although tau phosphorylation is frequently considered as one of the most important modifications leading to aggregation, emerging evidence has related N-terminal truncated tau to tau pathology. In fact, several specific truncations of tau have been identified in AD brains. Moreover, studies demonstrated that proteolytic cleavage of tau at N368, D421 and E391 increases its susceptibility to form NFTs [33,77]. Despite intense investigation, the precise pathogenesis of tau-mediated neurodegeneration in tauopathies still remains unclear. Although the accumulation of insoluble aggregated tau deposits in form of NFTs is considered as a pathological hallmark of tauopathies [78] with their regional distribution correlating with the severity of the cognitive decline in AD brains [79], the neurotoxicity of NFTs per se is controversial. Instead, recent evidence indicates that small soluble oligomeric forms of tau, generated during tangle formation, are the most toxic tau species causing neuron damage and synaptic dysfunction [80]. However, the toxic gain of function by NFTs might contribute to the disease progression as well [16]. Of note, increasing evidence has been linking tau pathology and neuroinflammation. Indeed, abnormal tau was associated with reactive microglia, as well as increased levels of pro-inflammatory cytokines (e.g., interleukin-1 $\beta$ ) and complement proteins (reviewed in [81]). The chronic neuroinflammation may lead to synapsic loss and cognitive decline. Interestingly, microglial cells themselves seem to be involved in the spreading of tau pathology [82].

Current therapeutic strategies targeting tau consist of anti-aggregation agents (regulation of tau phosphorylation, inhibition of tau aggregation), tau passive immunotherapy, tau therapeutic vaccines, targeting of tau gene expression (antisense therapies) and therapeutic reduction of tau (reviewed in [83]). Strikingly, the effects of tau-targeting drugs on mitochondrial function remain underinvestigated. Conversely, evidence showed that improving mitochondrial quality control via activation of mitophagy (removal of damaged mitochondria, see Section 3.2.) decreases tau pathology in different experimental models (reviewed in [84]). Namely, nicotinamide riboside supplementation (activator of mitophagy) was shown to decrease abnormal tau phosphorylation, neuroinflammation and cognitive impairments in AD transgenic animals $[85,86]$. Of note, mitophagy itself seems to play also a role in the regulation of the inflammatory response [87]. Further studies need to be performed to unravel the role of mitophagy in the reduction of tau pathology via modulation of neuroinflammation.

To our knowledge, only one of the tau-targeting agents undergoing clinical trials was shown to also have an effect on mitochondria [88]. Indeed, methylene blue (MB), also known as methylthionine chloride (MTC), is already an approved drug against malaria, and acts as a direct inhibitor of tau protein aggregation [83]. MTC was shown to counteract oxidative stress-induced mitochondrial damage, and to inhibit the monoamine oxidase A that is a source of reactive oxygen species (ROS) [88]. 
Despite the improvements observed in AD-related symptoms during phase II clinical trials, too many undesirable side effects were reported (e.g., dizziness, diarrhoea, painful urination) for the drug to be used (Clinical Trial Identifier, NCT00515333 and NCT00684944) [83].

\section{Mitochondria}

Mitochondria are complex cytosolic organelles in eukaryotic cells that have been known for over a century. Unlike other organelles, they are maternally inherited (although biparental inheritance of mitochondrial DNA was recently reported but still under debate $[89,90])$ and compartmentalized. Concerning their structural characteristics, mitochondria consist of a matrix and two membranes with an interjacent intermembrane space (IMS). The outer mitochondrial membrane (OMM) smoothly envelops and separates the organelle from the cytosol, whereas the inner mitochondrial membrane (IMM) is tightly folded, forming multiple invaginations termed as cristae. These organelles play a pivotal role in cell survival and death by regulating both energy metabolism and apoptotic pathways. Additionally, they contribute to an array of cellular functions, including intracellular calcium homeostasis, reduction-oxidation (redox) signaling, innate immunity, steroid biosynthesis and synaptic plasticity, to name a few [91,92]. In the following paragraphs, we will introduce key aspects of mitochondrial physiology that are relevant to understand the deleterious impact of abnormal tau on this paramount organelle (described in Sections 4 and 5).

\subsection{Mitochondrial Bioenergetics}

Despite this diversity of functions, mitochondria remain best known as the main source of cellular energy production in the form of adenosine triphosphate (ATP) via OXPHOS. OXPHOS refers to the metabolic process in which electrons are transferred stepwise to oxygen through a series of redox reactions between protein complexes to ultimately drive the synthesis of ATP. These protein complexes are embedded in the IMM and comprise four biochemically linked multi-subunit complexes (Complexes I, II, III and IV), known as the electron transport chain (ETC), and the ATP synthase (Complex V) [93]. Briefly, enzymes of the tricarboxylic acid cycle within the mitochondrial matrix oxidize acetyl-CoA, which is derived from carbohydrates, fats and proteins, to generate the reducing equivalents nicotinamide adenine dinucleotide $(\mathrm{NADH})$ and flavin adenine dinucleotide $\left(\mathrm{FADH}_{2}\right)$ [94] Subsequently, these molecules pass their electrons to the ETC. The following oxidation of these reduced substrates causes conformational changes in the respiratory chain Complexes I, III and IV, allowing them to pump protons $\left(\mathrm{H}^{+}\right)$out of the mitochondrial matrix into the IMS [95]. This in turn, produces a proton-gradient and thereby establishes an electrochemical potential, termed as mitochondrial membrane potential $(\Delta \Psi \mathrm{m})$ [2]. As a result, Complex V utilizes this proton motif force to catalyze the synthesis of ATP by phosphorylating adenosine diphosphate (ADP) [96] (Figure 1).

Although the physiological functions of mitochondria, such as the production of energy, are critical for cell survival, they also induce the formation of ROS that can pose serious damage to cells when generated in excess [1]. In order to avoid exceeding levels of ROS, cells possess efficient antioxidant mechanisms that scavenge ROS to non-toxic forms [97]. Consequently, under physiological conditions, the production and detoxification of ROS are balanced. However, an increased ROS production and/or a reduced antioxidant system can induce oxidative stress, which in turn damages proteins and DNA, and initiates lipid peroxidation. Since long polyunsaturated fatty acids chains of mitochondrial membranes exhibit a high susceptibility to oxidation, mitochondria represent the first targets of ROS toxicity, leading to depolarized membranes and damaged proteins, and consecutively to mitochondrial impairments. As a result, oxidative stress-induced mitochondrial dysfunction may initiate cell death, and has been implicated in the pathogenesis of many neurodegenerative diseases, including AD $[1,98,99]$. Namely, mitochondria-derived oxidative stress was proposed to be a causative factor for $A \beta$ and tau pathology $[1,98,100]$. Indeed, $A \beta$ load was increased in cells and mice that produced more ROS due to a mitochondrial Complex I inhibition/ deficiency [101]. Similarly, increased levels of tau and tau phosphorylation (at S396, S404, T205, T231) were observed in mice lacking the detoxifying enzyme 
superoxide dismutase 2 (SOD2) [102]. This suggests that mitochondrial dysfunction, more precisely mitochondria-derived ROS, might be involved in the pathogenesis of tauopathies.

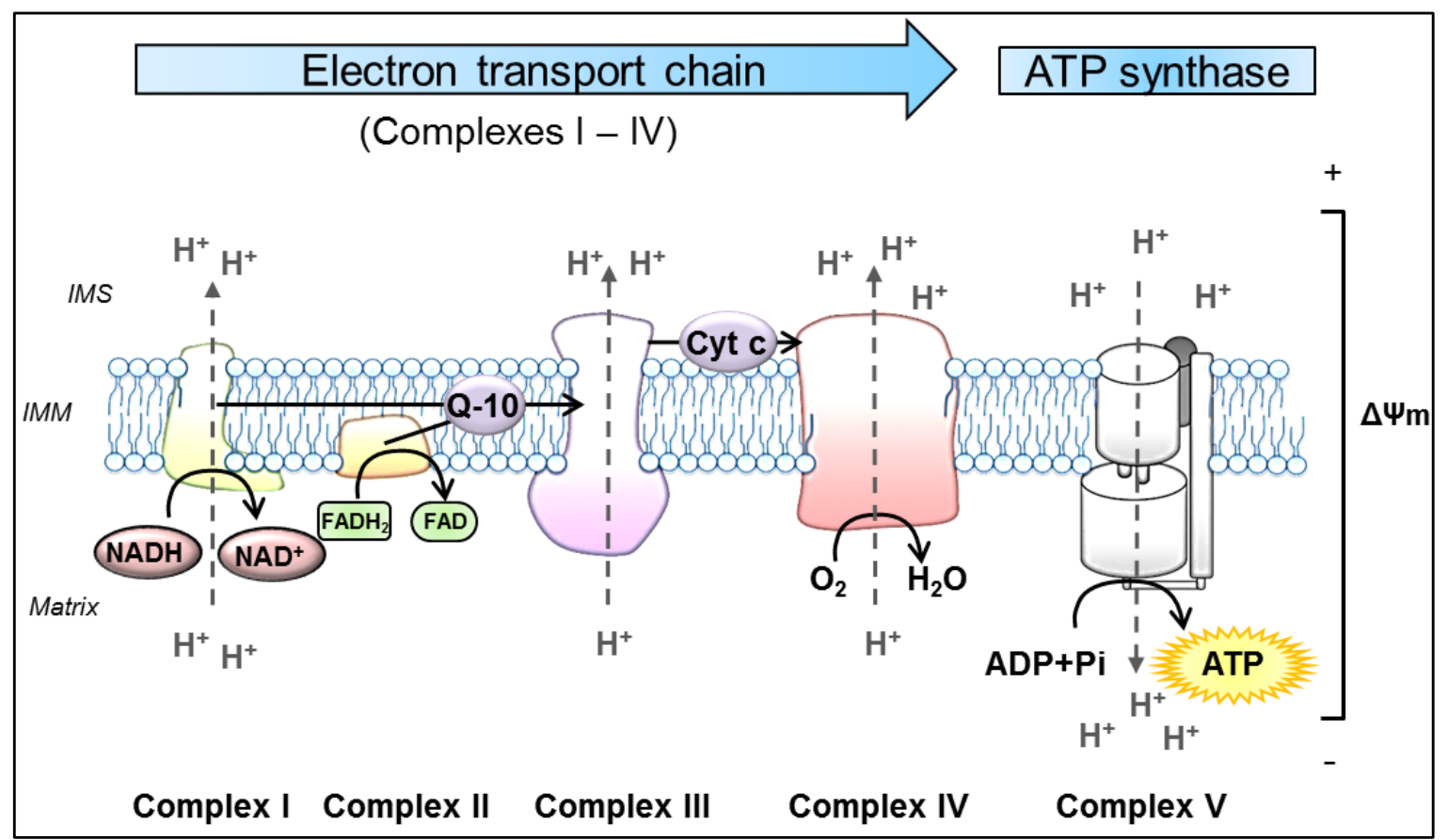

Figure 1. Schematic representation of oxidative phosphorylation (OXPHOS) in mitochondria. The process of OXPHOS is the main pathway in the cell to produce adenosine triphosphate (ATP). It consists of two coupled processes embedded in the inner mitochondrial membrane (IMM), the electron transport chain (ETC) and the ATP synthesis. In the ETC, the reduced substrates NADH and FADH 2 are oxidized by the NADH-ubiquinone oxidoreductase (Complex I) and succinate-CoenzymeQ reductase (Complex II), respectively. These proteins transfer electrons from their substrates onto Q-10, which serves as a substrate for the CoenzymeQ-cytochrome c oxidoreductase (Complex III). Q-10 is a highly lipophilic substance that is able to diffuse within the IMM. Complex III transfers the electrons from Q-10 onto cytochrome c, which is a water-soluble electron carrier, located at the surface of the IMM in the IMS. In the final step of the ETC, cytochrome c oxidase (Complex IV) uses the electrons from reduced Cyt $\mathrm{c}$ to reduce molecular oxygen to water. In the process of transferring electrons, the Complexes I, III and IV actively move protons $\left(\mathrm{H}^{+}\right)$from the mitochondrial matrix to the IMS, forming the $\Delta \Psi \mathrm{m}$. Ultimately, this potential is used by the ATP synthase (Complex V) to catalyze the generation of ATP from ADP and Pi. ADP: adenosine diphosphate, ATP: adenosine triphosphate, Cyt c: cytochrome c, ETC: electron transport chain, FADH2: flavin adenine dinucleotide, IMM: inner mitochondrial membrane, IMS: intermembrane space, NADH: nicotinamide adenine dinucleotide, Pi: inorganic phosphate, Q-10: coenzymeQ10, $\triangle \Psi \mathrm{m}$ : mitochondrial membrane potential.

\subsection{Mitochondrial Dynamics}

As commonly known, mitochondria are highly dynamic organelles that form a remarkably complex interconnected network, which varies greatly in different cell types. In response to external and internal stimuli, mitochondria are therefore able to adapt rapidly the degree to which they are networked [103]. Concretely, mitochondrial dynamics results from the interplay of processes, including mitochondrial biogenesis, mitochondrial fusion and fission, mitophagy, and mitochondrial trafficking (Figure 2). These processes maintain the mitochondrial homeostasis and regulate mitochondrial morphology and their distribution, ultimately being a vital component of the cellular stress response [104]. 


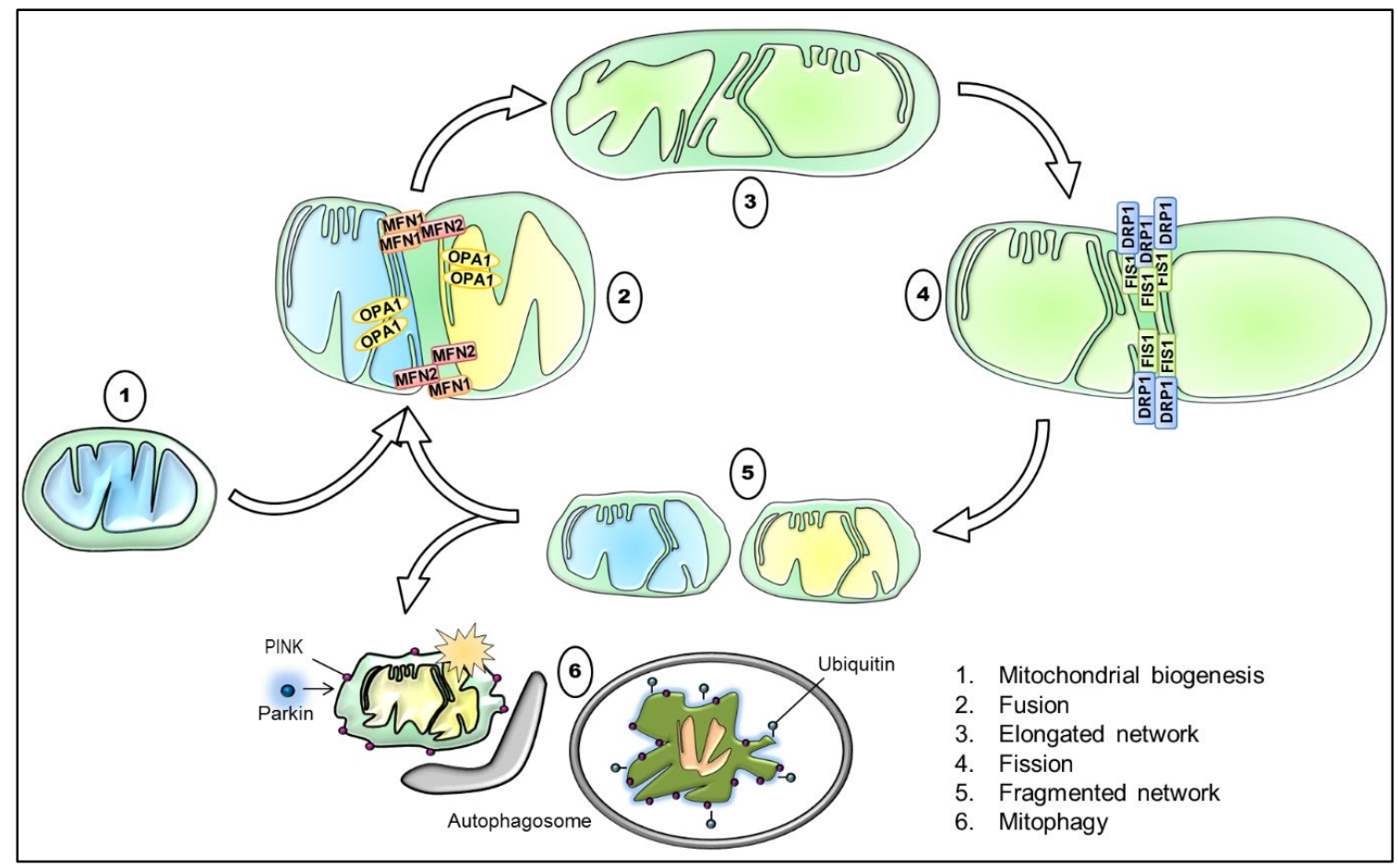

Figure 2. Schematic illustration of the interplay between mitochondrial biogenesis, fusion, fission, and mitophagy with key proteins involved. Briefly, mitochondrial biogenesis generates functional mitochondria, for instance in response to a reduced mitochondrial mass. The tethering of two mitochondria via the outer mitochondrial membrane (OMM) and IMM mediated through MFN1/MFN2 and OPA1, respectively, results in their fusion, and thus in the elongation of the mitochondrial network. Contrarily, the recruitment and orchestration of primarily DRP1 and assisting proteins, such as FIS1, causes mitochondrial division. Consequently, the process of mitochondrial fission promotes a more fragmented mitochondrial network and is required for the removal of damaged and dysfunctional mitochondria. Lastly, the accumulation of PINK1 and the subsequent recruitment of Parkin target defective mitochondria that are subsequently degraded by mitophagy. DRP1: dynamin-related protein 1, FIS1: mitochondrial fission protein 1, IMM: inner mitochondrial membrane, MFN1: mitofusin 1, MFN2: mitofusin 2, OMM: outer mitochondrial membrane, OPA1: optic atrophy 1, PINK1: PTEN-induced kinase 1.

The morphology of the cellular mitochondrial network is sustained by continuous rounds of fusion and fission. Consequently, the balance between these two opposite processes modulates mitochondrial number, shape and size [105]. While increased fusion generates elongated, interconnected mitochondria, enhanced fission promotes mitochondrial fragmentation. This plastic adaptation is particularly essential in neurons that are highly polarized cells. Since axons and dendrites have differential energy demands, the regulation of fusion and fission produces a generally more elongated network in the somatodendritic compartment and a more fragmented one in axons [106]. Notwithstanding, the mitochondrial integrity is fundamental for the mitochondrial metabolic activity and mitochondrial health. For instance, in fused organelles, the efficiency of ATP production is increased and the exchange of matrix content-including mitochondrial DNA - is favored. Fragmented organelles, in contrast, produce more ROS and are readily cleared by mitophagy. Nevertheless, mitochondrial fragmentation is indispensable during cell division for the equal distribution of mitochondria to daughter cells [107].

In mammalian cells, mitochondrial fusion involves the actions of three large dynamin-related guanosine triphosphatases (GTPases). While mitofusin 1 (MFN1) and 2 (MFN2) are the key mediators of the OMM fusion, optic atrophy 1 (OPA1) mediates the fusion of the IMM. Of note, OPA1 also regulates the remodeling of mitochondrial cristae, which is implicated in processes such as apoptosis [108]. Conversely, mitochondrial fission in mammalian cells is primarily orchestrated by dynamin-related protein 1 (DRP1), which is also a GTPase. In order to initiate mitochondrial fission, DRP1 needs to be 
recruited from the cytosol to mitochondria. This translocation depends on its phosphorylation state at S637. Whereas PKA-mediated phosphorylation of S637 retains DRP1 in the cytoplasm, $\mathrm{Ca}^{2+}$-dependent phosphatase calcineurin de-phosphorylation targets DRP1 to the OMM. This has been described to occur preferentially at regions associated with the ER. Subsequently, DRP1 oligomerizes into ring-like structures around mitochondria, providing the required mechanical fission force. As a consequence, guanosine triphosphate (GTP) hydrolysis induces membrane constriction, and thus facilitates scission. A series of additional proteins have been presented to recruit and assemble DRP1, and therefore assisting in the complete separation of mitochondria, including mitochondrial fission factor (MFF), mitochondrial dynamics protein 49 and 51 (MiD49/51), and mitochondrial fission 1 protein (FIS1). Although FIS1 was formerly identified as an essential regulator of mitochondrial fission, recent studies demonstrated that it appears to be dispensable for physiological fission. However, FIS1 may be involved in pathological fission processes. Since mitochondrial fusion and fission are crucial for the maintenance of cell survival, a pathological imbalance is associated with many disorders, such as neuropathies, brain injury, extreme stress conditions, aging, and neurodegenerative diseases [105,107,109]. Unsurprisingly, an altered balance of these processes has been reported in AD, both on transcript and protein levels $[110,111]$.

Beyond mitochondrial fusion and fission, another fundamental aspect involved in mitochondrial dynamics includes the regulation of mitochondrial trafficking. The proper subcellular distribution of mitochondria in neuronal cells is indispensable for ATP provisioning, axonal growth promotion, calcium buffering, and to ensure mitochondrial repair and degradation. In mammals, mitochondrial transport is mediated via the activities of the motor proteins dynein and kinesin, which are associated with the adaptor and receptor proteins of the OMM. Precisely, the transmembrane receptor protein mitochondrial Rho GTPase (Miro) interacts with the adaptor protein Milton that in turn tethers to motor proteins. Notably, when production of ATP and calcium buffering are required at specific sites, mitochondrial movement can be halted, and thus mitochondria are retained [112,113]. Accordingly, a loss of this Miro-Milton-dependent transport may cause depletion of mitochondria in dendrites and axons, giving arise to neurotransmission defects [114].

Equally important to fusion and fission, mitochondrial biogenesis and mitophagy regulate the dynamics of mitochondria. The balanced action of these two opposing cellular pathways determines the mitochondrial mass and accurate turnover, and is thus crucial for maintaining a healthy mitochondrial pool. Hence, the tight coordination of mitochondrial biogenesis and degradation is essential for the cellular adaptation in response to the cellular metabolic state, stress, and other intracellular or environmental signals $[115,116]$. During mitochondrial biogenesis, mitochondria increase their individual mass and copy number in order to either elevate mitochondrial function in general, or to compensate for decreased mitochondrial mass, resulted from higher rates of degradation. Damaged or energy-deficient mitochondria can be selectively degraded via mitochondrial autophagy, a process termed mitophagy. One of the best-characterized mitophagy pathways involves the operations of the proteins PTEN-induced kinase 1 (PINK1) and Parkin. The process of mitophagy is initiated, when dysfunctional fractions of the mitochondrial network cause a loss in $\Delta \Psi \mathrm{m}$. Although PINK1 is normally imported and degraded within the organelle, this depolarization results in the accumulation of PINK1 in the OMM. Accumulated PINK1 has been shown to phosphorylate ubiquitin in the OMM, consequently leading to the recruitment of the cytosolic ubiquitin ligase Parkin to the surface of mitochondria. Following translocation, activated Parkin ubiquitinylates proteins of the OMM. Subsequently, impaired mitochondria are recognized and engulfed into the autophagosome, ultimately targeted for lysosomal degradation $[113,117]$. Given the pivotal role of mitophagy in maintaining mitochondrial quality control and homeostasis, unsurprisingly, suppression or abnormalities of this process may result in the accumulation of damaged mitochondria. Indeed, mitochondrial dysregulation with regard to mitophagy has been implicated in several neurodegenerative diseases, including PD, $\mathrm{AD}$, and HD. Recent findings in AD patients with sporadic late-onset AD emphasized that mitophagy is compromised, leading to the accumulation of dysfunctional mitochondria, and thus contributing to synaptic dysfunction and cognitive deficits [118]. 


\section{Mitochondria: Target of Tau}

Abnormal tau impairs mitochondrial function, leading to neuronal degeneration, but the exact mechanisms are still not completely understood. In this section, we will discuss different impacts of abnormal tau on mitochondria in order to draw a "mitocentric" picture of tau toxicity. Noteworthy, nearly all the data discussed here derived from in vitro and animal studies. Therefore, studies performed on patients with tauopathies are highly needed, in order to confirm and fully apprehend mitochondrial dysfunctions induced by abnormal tau protein.

Important mitochondrial impairments observed in the presence of abnormal tau are summarized in Table 1 and Figure 3.

Table 1. Impacts of tau on mitochondrial function in vitro and in vivo.

\begin{tabular}{|c|c|c|c|}
\hline $\begin{array}{l}\text { Mitochondrial } \\
\text { Function }\end{array}$ & Model & $\begin{array}{c}\text { Main Impairments in the Presence of Abnormal Tau } \\
\text { Versus Respective Controls }\end{array}$ & Reference \\
\hline \multirow{5}{*}{ Transport } & $\begin{array}{c}\text { K3 mice } \\
\text { (human K369I mutant tau) }\end{array}$ & $\begin{array}{l}\text { Impairment in anterograde (not retrograde) transport of } \\
\text { mitochondria along the axon }\end{array}$ & [119] \\
\hline & $\begin{array}{l}\text { rTg4510 mice } \\
\text { (repressible human P301L } \\
\text { mutant tau) }\end{array}$ & $\begin{array}{l}\text { Decreased percentage of the cytoplasm occupied by } \\
\text { mitochondria } \\
\text { Reduction of mitochondrial content in neurites } \\
\text { Perinuclear clustering of mitochondria with no change } \\
\text { in mitochondrial volume }\end{array}$ & [120] \\
\hline & $\begin{array}{l}\text { PC12 cells and cortical neurons } \\
\text { expressing tau mutants: 3A } \\
\text { (non-phosphorylatable) and 3D } \\
\text { (phosphorylation mimic), with } \\
\text { mutations at the AT8 sites (S199, } \\
\text { S202, and T205) }\end{array}$ & $\begin{array}{l}\text { Increase in stationary mitochondria, decrease in the } \\
\text { velocity of mitochondrial movement } \\
\text { Increase in the inter-microtubular spacing affecting } \\
\text { mitochondrial movement }\end{array}$ & [121] \\
\hline & KI-P301L mice (P301L tau knock-in) & $\begin{array}{l}\text { Reduced number of axonal mitochondria } \\
\text { Increased volume of motile mitochondria in the axons } \\
\text { Impaired binding of tau to microtubules }\end{array}$ & [122] \\
\hline & $\begin{array}{l}\text { IPSC-derived neurons with tau } \\
\text { mutations }\end{array}$ & $\begin{array}{c}\text { Reduced number of axonal mitochondria and increase } \\
\text { retrograde transport (IPSCs with R406W tau mutation) } \\
\text { Decreased anterograde transport (IPSCs with N279K } \\
\text { and P301L tau mutations }\end{array}$ & {$[123,124]$} \\
\hline \multirow{3}{*}{ Dynamics } & $\begin{array}{l}\text { Drosophila expressing human } \\
\text { wild-type tau or human R406W } \\
\text { mutant tau } \\
\text { rTg4510 and } \mathrm{K} 3 \text { mice }\end{array}$ & $\begin{array}{l}\text { Excessive mitochondrial elongation } \\
\text { Increased actin stabilization and decreased localization } \\
\text { of dynamin-related protein } 1 \text { (DRP1) to mitochondria }\end{array}$ & [125] \\
\hline & $\begin{array}{c}\text { HEK293 cells and rat primary } \\
\text { hippocampal neurons expressing } \\
\text { the human wild-type full-length tau } \\
\text { (hTau) } \\
\text { hTau mice } \\
\text { (STOCK Mapttm1(EGFP)Klt } \\
\text { Tg(MAPT)8cPdav/J) }\end{array}$ & $\begin{array}{l}\text { Disruption of mitochondrial dynamics, enhanced fusion } \\
\text { and perinuclear accumulation of mitochondria } \\
\text { Increased expression of fusion proteins mitofusin } 1 \\
\text { (MFN1), mitofusin } 2 \text { (MFN2) and optic atrophy } 1 \\
\text { (OPA1), reduced ubiquitination of MFN2 }\end{array}$ & [126] \\
\hline & $\begin{array}{l}\text { SH-SY5Y cells stably overexpressing } \\
\text { wild-type (wt) and P301L } \\
\text { mutant tau }\end{array}$ & $\begin{array}{l}\text { Changes in mitochondrial morphology, decreased fusion } \\
\text { and fission rates } \\
\text { Clustering of mitochondria around the nucleus and } \\
\text { decreased mitochondrial movement }\end{array}$ & [127] \\
\hline \multirow{3}{*}{ Bioenergetics } & $\begin{array}{l}\text { pR5 mice } \\
\text { (human P301L mutant tau) }\end{array}$ & $\begin{array}{c}\text { Decreased mitochondrial respiration, mitochondrial } \\
\text { Complex I activity, adenosine triphosphate (ATP) levels } \\
\text { Increased reactive oxygen species (ROS) levels and } \\
\text { superoxide anion radicals }\left(\mathrm{O}_{2}{ }^{\bullet-}\right)\end{array}$ & {$[128,129]$} \\
\hline & $\begin{array}{l}\text { SH-SY5Y cells stably overexpressing } \\
\text { wild-type (wt) and P301L } \\
\text { mutant tau }\end{array}$ & $\begin{array}{c}\text { Decreased mitochondrial respiration, mitochondrial } \\
\text { Complex I activity, ATP levels, and mitochondrial } \\
\text { membrane potential }(\Delta \Psi \mathrm{m})\end{array}$ & $\begin{array}{l}{[127,130,} \\
131]\end{array}$ \\
\hline & $\begin{array}{l}\text { HEK293 cells expressing the human } \\
\text { wild-type full-length tau (hTau) } \\
\text { hTau mice }\end{array}$ & $\begin{array}{l}\text { Decreased mitochondrial Complex I activity, ATP levels, } \\
\text { and ATP/ ADP ratio }\end{array}$ & [126] \\
\hline mPTP & $\begin{array}{l}\text { Three-months-old tau knockout } \\
\text { (tau-/-) mice }\end{array}$ & $\begin{array}{l}\text { Inhibition of mitochondrial permeability transition pore } \\
\text { (mPTP) formation in the hippocampus, reduction of } \\
\text { cyclophilin D (CypD) protein level }\end{array}$ & [132] \\
\hline
\end{tabular}


Table 1. Cont.

\begin{tabular}{|c|c|c|c|}
\hline $\begin{array}{l}\text { Mitochondrial } \\
\text { Function }\end{array}$ & Model & $\begin{array}{c}\text { Main Impairments in the Presence of Abnormal Tau } \\
\text { Versus Respective Controls }\end{array}$ & Reference \\
\hline \multirow[t]{2}{*}{ Mitophagy } & $\begin{array}{c}\text { AD patients } \\
\text { hTau mice } \\
\text { HEK293 expressing hTau }\end{array}$ & $\begin{array}{l}\text { Increase of mitophagy markers (COX IV, TOMM20, ratio } \\
\text { mtDNA/ nDNA) } \\
\text { Dose-dependent allocation of tau proteins into the outer } \\
\text { mitochondrial membrane (OMM) } \\
\text { Increased } \Delta \Psi \mathrm{m} \text {, which impairs the mitochondrial } \\
\text { residence of PTEN-induced kinase } 1(\mathrm{PINK} 1) / \text { Parkin }\end{array}$ & [133] \\
\hline & $\begin{array}{c}\text { N2a cells and Caenorhabditis } \\
\text { elegans expressing human } \\
\text { wild-type (hTau) and P301L } \\
\text { mutant tau }\end{array}$ & $\begin{array}{l}\text { Decreased mitophagy } \\
\text { Sequestration of Parkin in the cytosol, preventing its } \\
\text { recruitment to defective mitochondria }\end{array}$ & [117] \\
\hline $\begin{array}{l}\text { Neuro- } \\
\text { steroidogenesis }\end{array}$ & $\begin{array}{l}\text { SH-SY5Y cells stably } \\
\text { overexpressing wild-type (wt) and } \\
\text { P301L mutant tau }\end{array}$ & Decreased pregnenolone synthesis & {$[131]$} \\
\hline
\end{tabular}

AD: Alzheimer's disease, COX IV: cytochrome c oxidase subunit IV, FTD: frontotemporal dementia, IPSCs: induced pluripotent stem cells, TOMM20: translocase of outer mitochondrial membrane 20, mtDNA/ nDNA: mitochondrial DNA/ nuclear DNA.

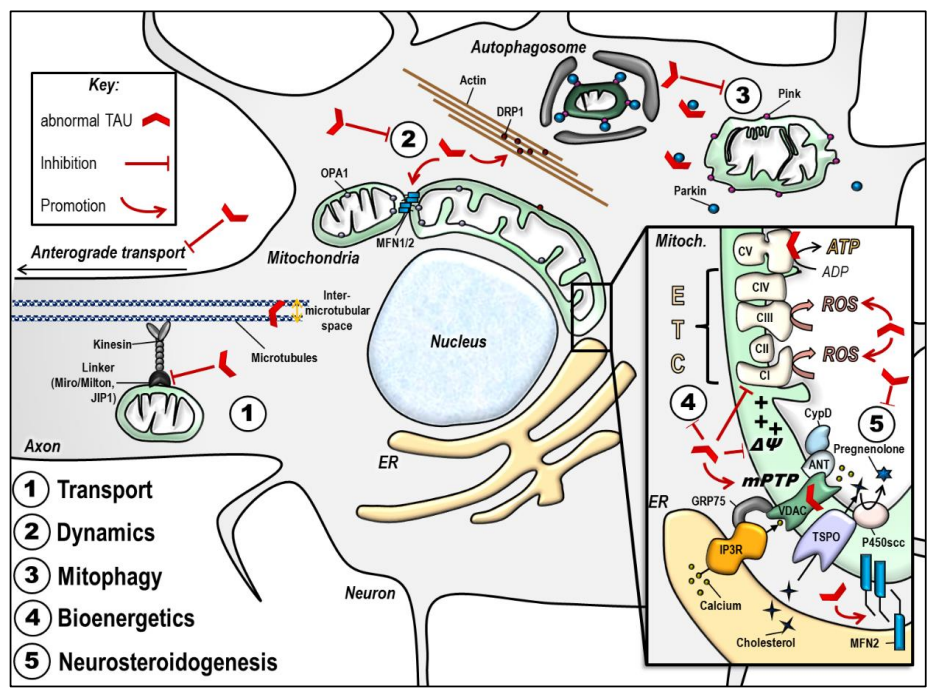

Figure 3. Abnormal tau protein impairs mitochondrial function. The scheme summarizes the impact of disease-associated tau protein on the different aspects of mitochondrial function (see details in the text). Of note, the effects illustrated here may be different according to tau models used (phospho-tau versus truncated tau). (1) Abnormal tau inhibits anterograde transport of mitochondria along the axon, leading to a decreased number of mitochondria at the synapse, and mitochondrial perinuclear clustering. (2) Abnormal tau seems to trigger mitochondrial network elongation by increasing MFN2 levels and by triggering DRP1 mislocalization and clustering in actin filaments. (3) Abnormal tau inhibits mitophagy by interacting with Parkin. (4) Abnormal tau disturbs mitochondrial bioenergetics by inhibiting Complex I activity, decreasing the $\triangle \Psi \mathrm{m}$ and ATP levels, and increasing ROS production. These effects may also be linked to abnormal tau impacts on the MPTP opening, and/ or to tau direct binding on mitochondrial proteins like voltage-dependent anion channel (VDAC) and subunits on the respiratory Complex V. (5) Abnormal tau disturbs mitochondrial steroidogenesis by decreasing pregnenolone synthesis. Finally, abnormal tau seems to impact on the ER-mitochondrial coupling, which may have consequences on all the above mentioned mitochondrial functions. ANT: adenine nucleotide translocator, ATP: adenosine triphosphate, CI-CV: respiratory complexes I-V, CypD: cyclophilin D, DRP1: dynamin-related protein 1, ER: endoplasmic reticulum, ETC: electron transport chain, GRP75: glucose-related protein 75, IP3R: inositol 3 phosphate receptor, JIP1: c-Jun N-terminal kinase-interacting protein 1, MFN1/ 2: mitofusin 1/ 2, mPTP: mitochondrial permeability transition pore, OPA1: optic atrophy 1, P450scc: cytochrome P450 cholesterol side-chain cleavage enzyme, ROS: reactive oxygen species, TSPO: translocator protein, VDAC: voltage-dependent anion channel, $\triangle \Psi \mathrm{m}$ : mitochondrial membrane potential. 


\subsection{Mitochondrial Transport}

Being a member of the family of MAPs, tau is involved in the transport of cargoes along the axons, including mitochondria. In K3 mice expressing the K369I tau mutation, anterograde axonal transport of mitochondria was impaired, reducing the number of mitochondria at the synapse [119]. Synaptic mitochondria play important roles in calcium buffering and fulfill the high energy required in this cellular compartment. Therefore, a decrease in mitochondrial transport to the synapse may lead to synaptic degeneration and neuronal death [106]. One proposed mechanism is that abnormal tau interacts with c-Jun N-terminal kinase-interacting protein 1 (JIP1), which is associated with the kinesin motor protein complex [134]. By sequestrating JIP1 in the cell body, abnormal tau impairs its transport to the axon, which disturbs the formation of the kinesin motor complex and impacts the kinesin-driven anterograde transport of mitochondria $[119,134]$. Of note, because abnormal tau leads to microtubule disassembly [135], it is not excluded that impairing the axonal microtubule tracks for the transport of cargoes impacts mitochondrial transport. Conversely, knockdown of Milton or Miro that are adaptor proteins involved in the axonal transport of mitochondria enhanced tau phosphorylation in transgenic Drosophila expressing human tau in a process involving partitioning defective-1 (PAR-1) protein and leading to neurodegeneration [136]. This indicates that a loss of axonal mitochondria promotes tau phosphorylation and neuronal degeneration. In PC12 cells and cortical mouse neurons, abnormal tau was shown to inhibit mitochondrial movement in the neurite processes [121]. In this model, abnormal tau did not disturb the interaction between kinesin and microtubules, but caused an increase in the inter-microtubular distance, affecting mitochondrial movement and velocity. In line, a decrease in mitochondrial content in the neurites was quantified in neurons from $\mathrm{rTg} 4510$ mice expressing the P301L tau mutation, paralleled with a perinuclear clustering of mitochondria [120]. Similarly, a $50 \%$ reduction in the number of mitochondria was observed in the axons of P301L tau knock-in mice (KI-P301L), which express the tau mutation at physiological levels [122]. Interestingly, in this model, P301L tau was found to be hypophosphorylated, indicating that defects in axonal transport may not be due to tau abnormal hyperphosphorylation. However, KI-P301L mice presented an increased volume of motile axonal mitochondria as well as impairments in tau binding on microtubules, which may disturb mitochondrial transport. Similar observations were made in SH-SY5Y cells stably overexpressing the wild-type (hTau40) and mutant (P301L) form of tau [127]. Cells bearing the mutant form of tau presented a decreased mitochondrial movement, abnormal mitochondrial morphology (cristae with globular structures and branched membranes), a clustering of mitochondria around the nucleus, as well as decreased fusion/ fission rates compared to wild-type tau expressing cells.

Impairments in mitochondrial axonal transport were also evident in induced pluripotent stem cells (IPSCs) derived from frontotemporal dementia (FTD) patients bearing the R406W tau mutation [124]. In these IPSCs induced into cerebral organoids, axonal mitochondria were less stationary and moved more in the retrograde direction, resulting in fewer mitochondria into the axon when compared to control cells. In line, anterograde axonal transport of mitochondria was significantly reduced in IPSC-derived neurons bearing the N279K and P301L tau mutation compared to controls [123].

Taken together, these findings show that abnormal tau affects the axonal transport of mitochondria, decreasing the number of mitochondria at the synapse, which may lead to synaptic degeneration.

\subsection{Mitochondrial Dynamics}

Mutant tau protein was shown to impair mitochondrial dynamics in vivo in Drosophila expressing human R406W tau as well as rTg4510 and K3 mice, leading to the elongation of the mitochondrial network [125]. This may be involved in the reduced mitochondrial mobility and transport, as elongated mitochondria are not easily transported, especially along the axon. One proposed mechanism is that F-actin stabilization is increased in the presence of tau, disturbing the physical association of DRP1 and mitochondria, leading to DRP1 mislocalization, excessive mitochondrial elongation and subsequent neurotoxicity. These findings were reproduced in a recent study showing that increased levels of leucine-rich repeat kinase 2 (LRRK2), which is involved in PD, enhanced tau neurotoxicity by 
stabilizing the actin cytoskeleton, promoting DRP1 mislocalization and mitochondrial elongation [137]. Interestingly, mitochondrial elongation was already observed at the early stages of tau pathology in THY-Tau22 mice, when hippocampal Ca1 neurons are enriched with tau oligomers [138]. In these mice, DRP1 levels were significantly decreased at six months of age compared to age-matched wild-type littermates, whereas no differences were observed at 12 months of age. Another study demonstrated that human wild-type tau (htau) overexpression disrupts mitochondrial dynamics and causes mitochondrial elongation by increasing fusion proteins OPA1, and MFN1/2, which decreases neuronal viability [126]. MFN2 knockdown reduced the htau-enhanced mitochondrial fusion and restored mitochondrial function, indicating that mitofusin-associated mitochondrial fusion may play a role in tau toxicity.

Intriguingly, expression of caspase-cleaved tau in immortalized cortical neurons, as well as in cortical neurons from tau-/- knockout mice, induced mitochondrial fragmentation paralleled with a decrease of OPA1 levels [139]. This indicates that abnormal tau phosphorylation and tau truncation may impair mitochondrial dynamics via distinct mechanisms that still need to be unraveled.

\subsection{Mitochondrial Bioenergetics}

Tau-induced bioenergetic deficits were first observed in pR5 mice (P301L tau mutant mice), in which proteomic analysis revealed a downregulation of subunits of the mitochondrial Complexes I and V, together with an age-dependent decrease in mitochondrial respiration, Complex I activity and ATP levels, as well as an increase in ROS when compared to wild-type littermates $[128,129]$. These findings were recapitulated in vitro in SH-SY5Y cells overexpressing P301L tau (P301L cells) [127]. In addition, $\mathrm{P} 301 \mathrm{~L}$ cells presented a decrease in the maximal respiration and in the spare respiratory capacity, as well as a decrease in the $\Delta \Psi \mathrm{m}$ when compared to wild-type tau overexpressing cells [130]. These data may be explained by the inhibition of Complex I activity induced by abnormal tau. In line, htau overexpression impaired mitochondrial bioenergetics by decreasing mitochondrial Complex I activity, ATP levels, as well as the ATP/ ADP ratio in HEK293 cells and hippocampus of htau mice compared to wild-type [126]. Interestingly, the genetic ablation of tau (tau-/-) significantly improved the bioenergetics capacity of mitochondria and reduced the oxidative damages in the hippocampus of young (three months old) mice, compared to age-matched wild-type littermates [132]. These improvements were paralleled with an increase in attentive capacity and exploratory ability in tau-/- mice, suggesting that preventing tau abnormal modifications enhances mitochondrial and brain functions.

A decrease in mitochondrial Complex I activity was also observed in the brain of $\mathrm{rTg} 4510$ mice, but was surprisingly paralleled with an increase in $\Delta \Psi \mathrm{m}$ [140]. This feature was recapitulated in an advanced human neuronal model: IPSCs-derived neurons from FTDP-17 patients carrying the $10+16$ mutation [141]. Compared to control IPSCs, FTDP-17 neurons presented a decrease in Complex I activity as well as in OXPHOS-derived ATP production, but an increased $\Delta \Psi \mathrm{m}$. One proposed mechanism is that hyperpolarization of mitochondria is due to Complex V working in reverse, leading to an increase in ROS production, oxidative stress and cell death.

Conversely, a recent report showed that tau decreases the $\Delta \Psi \mathrm{m}$ via mitochondrial membrane poration, which compromised organelle structural integrity, leading to the swelling of mitochondria [142]. In this study, mitochondria were isolated from SH-SY5Y neuroblastoma cells and treated with tau oligomers. The decrease in $\Delta \Psi \mathrm{m}$ was coupled with a release of cytochrome c. Intriguingly, the effects were independent of the mitochondrial permeability transition pore opening (mPTP), but rather due to the formation of non-selective ion-conducting tau nanopores caused by the binding of oligomeric tau on cardiolipin-rich membrane domains. These new data bring further insights into tau-induced mitochondrial toxicity. 


\subsection{Mitochondrial Permeability Transition Pore}

The MPTP is a key contributor to cell death and has been involved in the pathophysiology of several neurodegenerative diseases [143]. Indeed, upon mPTP opening, mitochondrial membranes become permeable, disrupting mitochondrial function and releasing apoptotic signals into the cytosol. The exact composition of the MPTP remains elusive, but several reports suggested that it comprises proteins like voltage-dependent anion channel (VDAC) and translocator protein (TSPO) in the OMM, adenine nucleotide translocator (ANT) in the IMM, and cyclophilin D (CypD) in the mitochondrial matrix (reviewed in [143]). As abnormal tau was shown to disturb the $\Delta \Psi \mathrm{m}$ in several models (see the previous section), one can suggest that these effects may be mediated by tau impacts on the MPTP.

Indeed, tau ablation inhibited mPTP formation in the hippocampus of three-months-old tau-/- mice by reducing the CypD protein level, compared to wild-type littermates [132]. Besides, tau was shown to directly interact with mitochondrial proteins, including subunits of the mitochondrial Complex V, which might explain bioenergetic deficits induced by abnormal tau, and VDAC [144]. In particular, phospho-tau interaction with VDAC was evident in the brain of AD patients at different Braak stages (I to V), as well as in 13-months-old APP/PS1 and 3xTgAD transgenic mice [145]. Furthermore, in our recent study, we showed that TSPO ligands increased the $\triangle \Psi \mathrm{m}$ in htau- and P301L tau-overexpressing SH-SY5Y cells [131]. We speculated that this effect was mediated by the ability of these ligands to modulate the $\mathrm{MPTP}$, although further investigations need to be conducted to determine the exact underlying mechanisms.

\subsection{Mitophagy}

Mitophagy plays a paramount role in mitochondrial quality control, by removing damaged mitochondria and ensuring a healthy mitochondrial population. In primary cultures of hippocampal neurons, the human 20-22 kDa NH2-tau fragment (NH2htau fragment mapping between 26 and 230 amino acids of the longest human tau isoform) was shown to increase mitophagic flux by recruiting Parkin to mitochondria, correlating with a decrease of synaptic stability [146,147], a feature also observed in human synaptic mitochondria from AD patients. In neurons expressing NH2htau, mitophagy inhibition partially prevented NH2htau-induced synaptic degeneration and neuronal death [147].

Other studies focusing on tau overexpression models showed that abnormal tau inhibits mitophagy $[117,133]$. Strikingly, an increase in the mitochondrial DNA/nuclear DNA ratio, as well as in mitophagy markers (COX IV and TOMM20), were observed in the brain of tau-positive AD patients, compared to tau-negative patients and healthy controls [133]. These data were recapitulated in vivo in htau transgenic mice, as well as in vitro in HEK293 and primary neurons overexpressing htau. In this study, htau overexpression induced an increase in the $\Delta \Psi \mathrm{m}$, preventing the recruitment of PINK/ Parkin to the mitochondrial fraction. Mitophagy deficits were rescued after Parkin overexpression in htau-overexpressing $\mathrm{H} 293$ cells. In line, using mitophagy reporters, Cummins and colleagues showed that both htau and P301L tau inhibited mitophagy in N2a cells and Caenorhabditis elegans [117]. Unlike the study previously described [137], the effects of tau on mitophagy were not due to changes in the $\Delta \Psi \mathrm{m}$, but to the sequestration of Parkin in the cytosol via interaction with the projection domain of tau. This sequestration prevented the recruitment of Parkin to mitochondria, inhibiting mitophagy. Interestingly, mitophagy stimulation reduced tau hyperphosphorylation in vitro (SH-SY5Y cells overexpressing 2N4R, 1N4R, 2N3R tau) and in vivo (transgenic nematodes expressing human tau and 3xTgAD mice), and reversed memory impairment in transgenic animals [86].

Together, these findings indicate that impaired mitophagy plays a role in tau pathogenesis, and highlight again distinct pathological features between models of tau phosphorylation and tau truncation. 


\section{New Insight on the Impact of Abnormal Tau on Neurosteroidogenesis and the ER-Mitochondria Coupling}

\subsection{Abnormal Tau and Neurosteroids}

We recently showed that abnormal tau also disturbs another mitochondrial function: the synthesis of neurosteroids or neurosteroidogenesis [131]. Indeed, steroids can be synthesized de novo in the brain from cholesterol, independently of the peripheral steroidogenic glands, and are then called "neuro"-steroids (reviewed in [148]). The first step of steroidogenesis takes place in mitochondria with the transfer of cholesterol from the cytosol to the mitochondrial matrix, and its conversion to pregnenolone (PREG), the precursor of all neurosteroids. PREG is then converted into other neurosteroids either in mitochondria or in the ER. In the nervous system, neurosteroids play important roles in the regulation of neuronal functions as they can act as allosteric modulators of neurotransmitter receptors (e.g., NMDA or GABA receptors) [149].

Decreased levels of neurosteroids were observed in AD brains [150-152]. In particular, the levels of the neurosteroids pregnenolone sulfate (PREGS) and dehydroepiandrosterone sulfate (DHEAS) were significantly reduced in the striatum, hypothalamus and cerebellum of AD patients compared to non-demented controls (postmortem analysis) [150]. Lower levels of PREG, dehydroepiandrosterone (DHEA), as well as PREGS and DHEAS, were also observed in the hippocampus, amygdala and frontal cortex of AD patients, and were negatively correlated with the presence of NFTs. Interestingly, another study showed that the neurosteroid allopregnanolone is reduced in the prefrontal cortex, and is inversely correlated with the patient's Braak stage, which reflects the evolution of tau pathology [151]. Together, these findings suggest a relationship between tau pathology, neurosteroids levels, and cognitive deficits, but the exact link remains elusive.

In our recent study, we showed that PREG levels were decreased in htau-overexpressing SH-SY5Y cells, and even more significantly reduced in P301L cells [131]. This effect was normalized in cells treated with TSPO ligands, which is involved in the first step of neurosteroidogenesis in mitochondria. The underlying mechanisms are currently under investigation in our laboratory. Nevertheless, we previously showed that neurosteroids, such as progesterone, estradiol, testosterone, DHEA and allopregnanolone, increase bioenergetics via the improvement of ATP production and mitochondrial respiration, and regulate the redox homeostasis in neuronal cells $[153,154]$. In particular, abnormal tau-induced mitochondrial impairments were reduced after treatment with progesterone, estradiol and testosterone [130].

Neuroprotective effects of a treatment with neurosteroids or sex-hormones-derived neuroactive steroids were evident against cognitive and bioenergetics deficits observed in $\mathrm{AD}$ (reviewed in $[99,155]$ ). In particular, allopregnanolone induces neurogenesis, restores learning and memory function, shows a trend to decrease phospho-tau levels, and reverses bioenergetic deficits in 3xTgAD transgenic mice [155-158]. Allopregnanolone is currently undergoing clinical trials for the treatment of AD [159].

As the effects of neurosteroids in other tauopathies are less studied and remain elusive, the use of these molecules as therapeutic agents against abnormal tau-induced neurodegeneration would deserve more attention in future investigations.

\subsection{Abnormal Tau and ER-Mitochondria Coupling}

Mitochondria are closely connected to ER membranes, forming a highly dynamic platform termed as mitochondria-associated ER membranes (MAMs). Particularly, up to $20 \%$ of the mitochondrial surface associates with ER membranes, allowing tight communication physically and biochemically. Accordingly, MAMs provide an outstanding scaffold for the crosstalk between mitochondria and the ER, playing a crucial role in different signaling pathways that require a rapid exchange of metabolites for the maintenance of cellular health. Moreover, numerous proteins have been revealed to be enriched in MAMs, participating in the regulation of many fundamental cellular pathways. Therefore, MAM crosstalk is involved in a variety of processes, including cholesterol metabolism, 
calcium homeostasis, phospholipid metabolism, the transfer of lipids between these two organelles, and the regulation of mitochondrial bioenergetics and dynamics. Besides, MAM coupling affects autophagy, ER-stress, inflammation and finally apoptosis [160-163]. In view of contributing to so many functions, it is hardly surprising that MAMs have drawn great attention in the studying of cell homeostasis and dysfunction, especially in the context of neurodegenerative disaeses. Strikingly, an increasing number of disease-associated proteins have been demonstrated to interact with MAMs, thereby regionally inducing structural and functional perturbations [164].

Mounting evidence emphasizes the role of a disturbed ER-mitochondria interconnection in neurodegenerative diseases such as AD, FTD and amyotrophic lateral sclerosis (ALS) (reviewed in [161]). For instance, in A $\beta$-related AD models, impairments in the ER-mitochondria coupling are translated by: (i) an increase in the expression of MAMs proteins and in the number ER-mitochondria contact points [165]; (ii) an upregulation in MAMs function including phospholipid and cholesterol synthesis [165,166]; and (iii) disturbed calcium homeostasis triggering a pathological cascade of events leading to apoptosis $[160,167]$. In amyotrophic lateral sclerosis with associated frontotemporal dementia (ALS/ FTD), TAR DNA-binding protein 43 (TDP-43) was shown to loosen ER-mitochondria contacts by disturbing the link between vesicle-associated membrane protein-associated protein $B$ (VAPB) at the ER membrane and protein tyrosine phosphatase interacting protein 51 (PTPIP51) at the mitochondrial membrane, two proteins involved in MAMs tethering $[161,168]$. This disruption of the ER-mitochondria interaction disturbed the calcium exchange between both organelles, and may be linked to the decrease in ATP levels leading to motor neuron degeneration [168,169].

Until recently, only one study had focused on the impact of abnormal tau on the ER-mitochondria interaction [170]. Indeed, using electron microscopy techniques, Perreault and colleagues showed a higher number of ER-mitochondria contact points in a tau transgenic mouse model (JNPL3, P301L tau transgenic mice) compared to wild-type animals. An increased association of hyperphosphorylated tau with ER membranes was also observed in post-mortem brains of AD patients, suggesting that the ER-mitochondria axis may also play a role in abnormal tau-induced neurodegeneration. In line, Cieri et al. showed that overexpression of caspase 3-cleaved $2 \mathrm{~N} 4 \mathrm{R} \Delta \mathrm{C}_{20}$ tau in Hela cells increased the number of tight (8-10 nm) ER-mitochondria contact points, whereas long-range (40-50 nm) interactions were not affected [171]. In parallel, truncated $\left(2 \mathrm{~N} 4 \mathrm{R} \Delta \mathrm{C}_{20}\right)$ and full length (2N4R) tau expression affected the ER calcium storage, suggesting that tau may disturb the MAMs leading to ER calcium mishandling. Interestingly, tau was also found at the OMM and within the IMS, but not in the mitochondrial matrix.

With the aim to characterize the link between ER-stress and bioenergetic defects in the presence of tau, we recently showed that P301L expressing SH-SY5Y cells presented a highly activated unfolded protein response (UPR $=$ ER-stress) and dysregulated mitochondrial bioenergetics in basal condition, when compared to wtTau cells [172]. Furthermore, acute ER-stress was induced using thapsigargin, which increased the activity of the UPR in both wtTau and P301L tau cells, leading to the upregulation of apoptotic pathways, and further dysregulated mitochondrial function. This study supports the role of close communication between mitochondria and the ER during apoptosis in tauopathies.

Further investigations are now needed to unravel the underlying mechanisms, as well as potential effects of abnormal tau on other MAM functions (e.g., cholesterol and phospholipid homeostasis), which may highlight potential therapeutic targets. For instance, in ALS/ FTD, TDP-43 was shown to induce the activation of GSK $3 \beta$, which then disrupts the binding of PTPIP51 and VAPB (reviewed in [161]). Since GSK $3 \beta$ is also involved in tau phosphorylation and is up-regulated in AD $[173,174]$, it constitutes a good candidate against tauopathies. However, whether GSK $3 \beta$ is involved in impairments of the ER-mitochondria coupling in abnormal tau-related diseases remains to be determined.

\section{Conclusions}

In summary, abnormal tau has an impact on all aspects of mitochondrial functions, from mitochondrial transport and dynamics, to bioenergetics and mitophagy (Figures 3 and 4). Because mitochondria 
play a pivotal role in neuron life and death [1], alteration in their function leads to neuronal dysfunction and death, and eventually to dementia. Besides, given that mitochondria are not isolated, self-autonomous organelles floating in the cytosol, but on the contrary highly interconnected with other cellular compartments, including the ER, it is not surprising that abnormal tau-induced mitochondrial dysfunction affects other cellular functions, and vice versa. It is, however, important to note that discrepancies are sometimes observed between tau models. Common features were observed with regards to mitochondrial bioenergetics (decreased ATP levels, Complex I inhibition) and transport (impaired axonal transport, perinuclear clustering), but different findings were obtained concerning the $\Delta \Psi \mathrm{m}$ (increased or decreased $\Delta \Psi \mathrm{m}$ in the presence of tau), mitochondrial dynamics (tau-induced mitochondrial elongation or fragmentation) and mitophagy (triggered or inhibited by tau). Strikingly, these differences are often linked with the type of tau used in the study (phospho-tau or truncated tau). These two aspects of tau pathology should be considered to fully understand the molecular mechanisms underlying tauopathies, and are therefore important to highlight therapeutic targets.

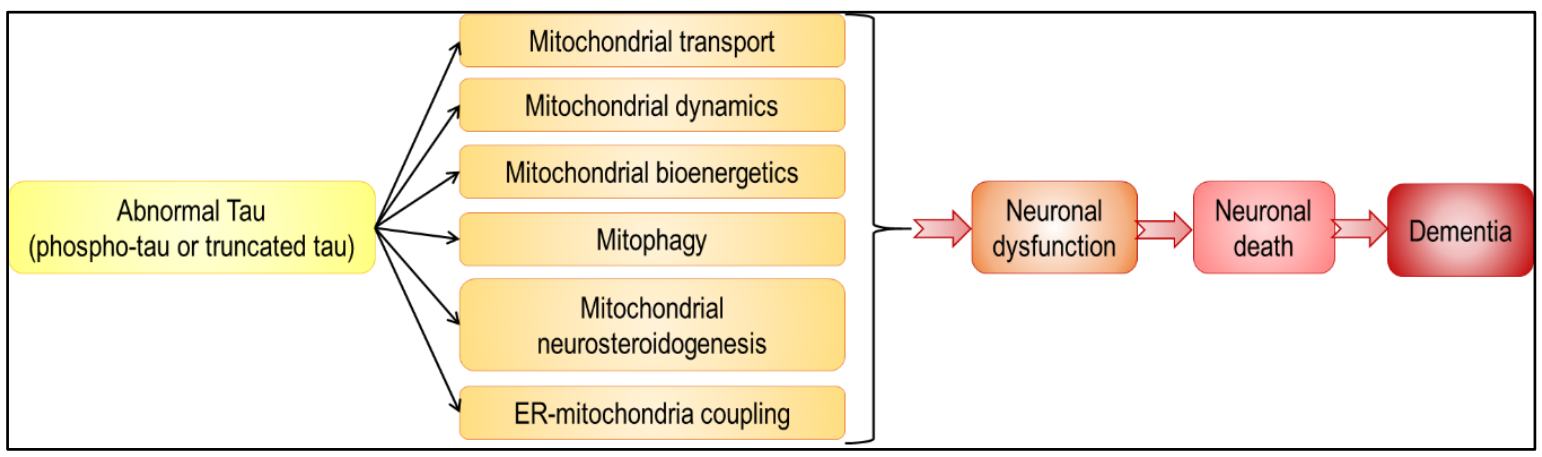

Figure 4. Abnormal tau-induced mitochondrial impairments may lead to neuronal death and dementia. Abnormal tau was shown to have a negative impact on all aspects of mitochondrial function (black arrows). These tau-induced disturbances may lead to various neuronal dysfunctions, ranging from subtle alterations in neuronal physiology to cell death and neurodegeneration (red arrows).

Author Contributions: Conceptualization, A.G. and A.E.; writing—original draft preparation, and editing, L.S., A.G. and A.E.; creation of figures, L.S. and A.G., funding acquisition, A.G. and A.E. All authors have read and agreed to the published version of the manuscript.

Funding: This research was funded by the Synapsis Foundation, Alzheimer Research Switzerland to A.G., Universität Basel Forschungsfonds to A.G., and the Swiss National Science Foundation (\#31003A_179294) to A.E.

Conflicts of Interest: The authors declare no conflict of interest.

\section{Abbreviations}

$\mathrm{AD}$

ADP

ALS

ALS/ FTD

AMPK

ANT

ATP

$\mathrm{A} \beta$

CaMKII

CBD

Cdk5

COX IV

CTE

CypD
Alzheimer's disease

adenosine diphosphate

amyotrophic lateral sclerosis

amyotrophic lateral sclerosis with associated frontotemporal dementia

$5^{\prime}$ adenosine monophosphate-activated protein kinase

adenine nucleotide translocator

adenosine triphosphate

amyloid- $\beta$

calcium/ calmodulin-dependent protein kinase II

corticobasal degeneration

cyclin-dependent kinase 5

cytochrome c oxidase subunit IV

Chronic Traumatic Encephalopathy

cyclophilin D 


\begin{tabular}{|c|c|}
\hline DHEA & dehydroepiandrosterone \\
\hline DHEAS & dehydroepiandrosterone sulfate \\
\hline DRP1 & dynamin-related protein 1 \\
\hline ER & endoplasmic reticulum \\
\hline ETC & electron transport chain \\
\hline $\mathrm{FADH}_{2}$ & flavin adenine dinucleotide \\
\hline FIS1 & mitochondrial fission 1 protein \\
\hline FTD & frontotemporal dementia \\
\hline FTDP-17 & frontotemporal dementia with parkinsonism-17 \\
\hline FTLD & frontotemporal lobar degeneration \\
\hline GRP75 & glucose-related protein 75 \\
\hline GSK $3 \alpha / \beta$ & glycogen synthase kinase $3 \alpha / \beta$ \\
\hline GTP & guanosine triphosphate \\
\hline GTPase & dynamin-related guanosine triphosphatase \\
\hline HD & Huntington's disease \\
\hline IMM & inner mitochondrial membrane \\
\hline IMS & intermembrane space \\
\hline IPSCs & induced-pluripotent stem cells \\
\hline JIP1 & c-Jun N-terminal kinase-interacting protein 1 \\
\hline IP3R & inositol 3 phosphate receptor \\
\hline LRRK2 & leucine-rich repeat kinase 2 \\
\hline MAMs & mitochondria-associated ER membranes \\
\hline MAPKs & mitogen-activated protein kinases \\
\hline MAPs & microtubule-associated proteins \\
\hline MAPT & microtubule-associated protein tau \\
\hline MB & methylene blue \\
\hline MFF & mitochondrial fission factor \\
\hline MFN1/ 2 & mitofusin $1 / 2$ \\
\hline MiD49/ 51 & mitochondrial dynamics protein $49 / 51$ \\
\hline Miro & mitochondrial Rho GTPase \\
\hline mPTP & mitochondrial permeability transition pore \\
\hline MTC & methylthionine chloride \\
\hline NADH & nicotinamide adenine dinucleotide \\
\hline NFTs & neurofibrillary tangles \\
\hline NH2htau & NH2-truncated human tau fragment \\
\hline $\mathrm{O}_{2}^{\bullet-}$ & superoxide anion radical \\
\hline OMM & outer mitochondrial membrane \\
\hline OPA1 & optic atrophy 1 \\
\hline OXPHOS & oxidative phosphorylation system \\
\hline PAR-1 & partitioning defective- 1 \\
\hline PD & Parkinson's disease \\
\hline PHFs & paired helical filaments \\
\hline PINK1 & PTEN-induced kinase 1 \\
\hline PKA & cAMP-dependent protein kinase A \\
\hline PKC & protein kinase $\mathrm{C}$ \\
\hline $\mathrm{PP}$ & protein phosphatase \\
\hline PREG & pregnenolone \\
\hline PREGS & pregnenolone sulfate \\
\hline PSP & progressive supranuclear palsy \\
\hline PTPIP51 & protein tyrosine phosphatase interacting protein 51 \\
\hline P450scc & cytochrome P450 cholesterol side chain cleavage enzyme \\
\hline redox & reduction-oxidation \\
\hline ROS & reactive oxygen species \\
\hline SOD2 & superoxide dismutase 2 \\
\hline TDP-43 & TAR DNA-binding protein 43 \\
\hline
\end{tabular}




$\begin{array}{ll}\text { TOMM20 } & \text { translocase of outer mitochondrial membrane } 20 \\ \text { TSPO } & \text { translocator protein } \\ \text { TTBK1/ } 2 & \text { tau-tubulin kinase } 1 / 2 \\ \text { UPR } & \text { unfolded protein response } \\ \text { VAPB } & \text { vesicle-associated membrane protein-associated protein B } \\ \text { VDAC } & \text { voltage-dependent anion channel } \\ \triangle \Psi m & \text { mitochondrial membrane potential }\end{array}$

\section{References}

1. Grimm, A.; Eckert, A. Brain aging and neurodegeneration: From a mitochondrial point of view. J. Neurochem. 2017, 143, 418-431. [CrossRef]

2. Zorova, L.D.; Popkov, V.A.; Plotnikov, E.Y.; Silachev, D.N.; Pevzner, I.B.; Jankauskas, S.S.; Babenko, V.A.; Zorov, S.D.; Balakireva, A.V.; Juhaszova, M.; et al. Mitochondrial membrane potential. Anal. Biochem. 2018, 552, 50-59. [CrossRef]

3. Schmitt, K.; Grimm, A.; Kazmierczak, A.; Strosznajder, J.B.; Götz, J.; Eckert, A. Insights into mitochondrial dysfunction: Aging, amyloid-beta, and tau-A deleterious trio. Antioxid. Redox Signal. 2012, 16, 1456-1466. [CrossRef]

4. Wu, Y.; Chen, M.; Jiang, J. Mitochondrial dysfunction in neurodegenerative diseases and drug targets via apoptotic signaling. Mitochondrion 2019, 49, 35-45. [CrossRef]

5. Tapia-Rojas, C.; Cabezas-Opazo, F.; Deaton, C.A.; Vergara, E.H.; Johnson, G.V.W.; Quintanilla, R.A. It's all about tau. Prog. Neurobiol. 2019, 175, 54-76. [CrossRef]

6. Cheng, Y.; Bai, F. The Association of Tau With Mitochondrial Dysfunction in Alzheimer's Disease. Front. Neurosci. 2018, 12. [CrossRef]

7. Pérez, M.J.; Jara, C.; Quintanilla, R.A. Contribution of Tau Pathology to Mitochondrial Impairment in Neurodegeneration. Front. Neurosci. 2018, 12. [CrossRef]

8. Bodea, L.-G.; Eckert, A.; Ittner, L.M.; Piguet, O.; Götz, J. Tau physiology and pathomechanisms in frontotemporal lobar degeneration. J. Neurochem. 2016, 138, 71-94. [CrossRef]

9. Götz, J.; Halliday, G.; Nisbet, R.M. Molecular Pathogenesis of the Tauopathies. Annu. Rev. Pathol. Mech. Dis. 2019, 14, 239-261. [CrossRef]

10. Wang, Y.; Mandelkow, E. Tau in physiology and pathology. Nat. Rev. Neurosci. 2016, 17, 22-35. [CrossRef]

11. Arendt, T.; Stieler, J.T.; Holzer, M. Tau and tauopathies. Brain Res. Bull. 2016, 126, 238-292. [CrossRef]

12. Neve, R.L.; Harris, P.; Kosik, K.S.; Kurnit, D.M.; Donlon, T.A. Identification of cDNA clones for the human microtubule-associated protein tau and chromosomal localization of the genes for tau and microtubule-associated protein 2. Mol. Brain Res. 1986, 1, 271-280. [CrossRef]

13. Goedert, M.; Spillantini, M.G.; Jakes, R.; Rutherford, D.; Crowther, R.A. Multiple isoforms of human microtubule-associated protein tau: Sequences and localization in neurofibrillary tangles of Alzheimer's disease. Neuron 1989, 3, 519-526. [CrossRef]

14. Goedert, M.; Spillantini, M.G.; Potier, M.C.; Ulrich, J.; Crowther, R.A. Cloning and sequencing of the cDNA encoding an isoform of microtubule-associated protein tau containing four tandem repeats: Differential expression of tau protein mRNAs in human brain. Embo. J. 1989, 8, 393-399. [CrossRef]

15. Lee, G.; Neve, R.L.; Kosik, K.S. The microtubule binding domain of tau protein. Neuron 1989, 2, 1615-1624. [CrossRef]

16. Ballatore, C.; Lee, V.M.Y.; Trojanowski, J.Q. Tau-mediated neurodegeneration in Alzheimer's disease and related disorders. Nat. Rev. Neurosci. 2007, 8, 663-672. [CrossRef]

17. Hong, M.; Zhukareva, V.; Vogelsberg-Ragaglia, V.; Wszolek, Z.; Reed, L.; Miller, B.I.; Geschwind, D.H.; Bird, T.D.; McKeel, D.; Goate, A.; et al. Mutation-Specific Functional Impairments in Distinct Tau Isoforms of Hereditary FTDP-17. Science 1998, 282, 1914-1917. [CrossRef]

18. Lebouvier, T.; Pasquier, F.; Buée, L. Update on tauopathies. Curr. Opin. Neurol. 2017, 30, 589-598. [CrossRef]

19. Goedert, M.; Jakes, R. Expression of separate isoforms of human tau protein: Correlation with the tau pattern in brain and effects on tubulin polymerization. Embo. J. 1990, 9, 4225-4230. [CrossRef] 
20. Stoothoff, W.; Jones, P.B.; Spires-Jones, T.L.; Joyner, D.; Chhabra, E.; Bercury, K.; Fan, Z.; Xie, H.; Bacskai, B.; Edd, J.; et al. Differential effect of three-repeat and four-repeat tau on mitochondrial axonal transport. J. Neurochem. 2009, 111, 417-427. [CrossRef]

21. Friedhoff, P.; von Bergen, M.; Mandelkow, E.-M.; Mandelkow, E. Structure of tau protein and assembly into paired helical filaments. Biochim. Biophys. Acta (Bba) Mol. Basis Dis. 2000, 1502, 122-132. [CrossRef]

22. Guo, T.; Noble, W.; Hanger, D.P. Roles of tau protein in health and disease. Acta Neuropathol. 2017, 133, 665-704. [CrossRef]

23. Mandelkow, E.-M.; Mandelkow, E. Biochemistry and cell biology of tau protein in neurofibrillary degeneration. Cold Spring Harb Perspect Med. 2012, 2, a006247. [CrossRef]

24. Gustke, N.; Trinczek, B.; Biernat, J.; Mandelkow, E.M.; Mandelkow, E. Domains of tau Protein and Interactions with Microtubules. Biochemistry 1994, 33, 9511-9522. [CrossRef]

25. Brandt, R.; Léger, J.; Lee, G. Interaction of tau with the neural plasma membrane mediated by tau's amino-terminal projection domain. J. Cell Biol. 1995, 131, 1327-1340. [CrossRef]

26. Goedert, M. Tau filaments in neurodegenerative diseases. FEBS Lett. 2018, 592, 2383-2391. [CrossRef]

27. Chen, J.; Kanai, Y.; Cowan, N.J.; Hirokawa, N. Projection domains of MAP2 and tau determine spacings between microtubules in dendrites and axons. Nature 1992, 360, 674-677. [CrossRef]

28. Lee, G.; Newman, S.T.; Gard, D.L.; Band, H.; Panchamoorthy, G. Tau interacts with src-family non-receptor tyrosine kinases. J. Cell Sci. 1998, 111, 3167-3177.

29. Kadavath, H.; Hofele, R.V.; Biernat, J.; Kumar, S.; Tepper, K.; Urlaub, H.; Mandelkow, E.; Zweckstetter, M. Tau stabilizes microtubules by binding at the interface between tubulin heterodimers. Proc. Natl. Acad. Sci. USA 2015, 112, 7501-7506. [CrossRef]

30. Mandelkow, E.; von Bergen, M.; Biernat, J.; Mandelkow, E.-M. Structural Principles of Tau and the Paired Helical Filaments of Alzheimer?s Disease. Brain Pathol. 2007, 17, 83-90. [CrossRef]

31. Jeganathan, S.; von Bergen, M.; Mandelkow, E.-M.; Mandelkow, E. The Natively Unfolded Character of Tau and Its Aggregation to Alzheimer-like Paired Helical Filaments. Biochemistry 2008, 47, 10526-10539. [CrossRef]

32. Jeganathan, S.; von Bergen, M.; Brutlach, H.; Steinhoff, H.-J.; Mandelkow, E. Global Hairpin Folding of Tau in Solution. Biochemistry 2006, 45, 2283-2293. [CrossRef]

33. Zhou, Y.; Shi, J.; Chu, D.; Hu, W.; Guan, Z.; Gong, C.-X.; Iqbal, K.; Liu, F. Relevance of Phosphorylation and Truncation of Tau to the Etiopathogenesis of Alzheimer's Disease. Front. Aging Neurosci. 2018, 10, 27. [CrossRef]

34. Wang, Y.P.; Biernat, J.; Pickhardt, M.; Mandelkow, E.; Mandelkow, E.M. Stepwise proteolysis liberates tau fragments that nucleate the Alzheimer-like aggregation of full-length tau in a neuronal cell model. Proc. Natl. Acad. Sci. USA 2007, 104, 10252-10257. [CrossRef]

35. Mietelska-Porowska, A.; Wasik, U.; Goras, M.; Filipek, A.; Niewiadomska, G. Tau protein modifications and interactions: Their role in function and dysfunction. Int. J. Mol. Sci. 2014, 15, 4671-4713. [CrossRef]

36. Stancu, I.-C.; Ferraiolo, M.; Terwel, D.; Dewachter, I. Tau Interacting Proteins: Gaining Insight into the Roles of Tau in Health and Disease. In Tau Biology; Takashima, A., Wolozin, B., Buee, L., Eds.; Springer: Singapore, 2019; pp. 145-166.

37. Kanemaru, K.; Takio, K.; Miura, R.; Titani, K.; Ihara, Y. Fetal-Type Phosphorylation of the $\tau$ in Paired Helical Filaments. J. Neurochem. 1992, 58, 1667-1675. [CrossRef]

38. Hanger, D.P.; Anderton, B.H.; Noble, W. Tau phosphorylation: The therapeutic challenge for neurodegenerative disease. Trends Mol. Med. 2009, 15, 112-119. [CrossRef]

39. Martin, L.; Latypova, X.; Terro, F. Post-translational modifications of tau protein: Implications for Alzheimer's disease. Neurochem. Int. 2011, 58, 458-471. [CrossRef]

40. Leroy, K.; Yilmaz, Z.; Brion, J.-P. Increased level of active GSK-3 $\beta$ in Alzheimer's disease and accumulation in argyrophilic grains and in neurones at different stages of neurofibrillary degeneration. Neuropathol. Appl. Neurobiol. 2007, 33, 43-55. [CrossRef]

41. Liu, F.; Grundke-Iqbal, I.; Iqbal, K.; Gong, C.-X. Contributions of protein phosphatases PP1, PP2A, PP2B and PP5 to the regulation of tau phosphorylation. Eur. J. Neurosci. 2005, 22, 1942-1950. [CrossRef]

42. Binder, L.I.; Frankfurter, A.; Rebhun, L.I. The distribution of tau in the mammalian central nervous system. J. Cell Biol. 1985, 101, 1371-1378. [CrossRef]

43. Morris, M.; Maeda, S.; Vossel, K.; Mucke, L. The many faces of tau. Neuron 2011, 70, 410-426. [CrossRef] 
44. Igaev, M.; Janning, D.; Sündermann, F.; Niewidok, B.; Brandt, R.; Junge, W. A refined reaction-diffusion model of tau-microtubule dynamics and its application in FDAP analysis. Biophys. J. 2014, 107, 2567-2578. [CrossRef]

45. Cabrales Fontela, Y.; Kadavath, H.; Biernat, J.; Riedel, D.; Mandelkow, E.; Zweckstetter, M. Multivalent cross-linking of actin filaments and microtubules through the microtubule-associated protein Tau. Nat. Commun. 2017, 8, 1981. [CrossRef]

46. Kadavath, H.; Cabrales Fontela, Y.; Jaremko, M.; Jaremko, Ł.; Overkamp, K.; Biernat, J.; Mandelkow, E.; Zweckstetter, M. The Binding Mode of a Tau Peptide with Tubulin. Angew. Chem. Int. Ed. 2018, 57, 3246-3250. [CrossRef]

47. Amos, L.A. Microtubule structure and its stabilisation. Org. Biomol. Chem. 2004, 2, 2153-2160. [CrossRef]

48. Mazanetz, M.P.; Fischer, P.M. Untangling tau hyperphosphorylation in drug design for neurodegenerative diseases. Nat. Rev. Drug Discov. 2007, 6, 464-479. [CrossRef]

49. Duan, Y.; Dong, S.; Gu, F.; Hu, Y.; Zhao, Z. Advances in the Pathogenesis of Alzheimer's Disease: Focusing on Tau-Mediated Neurodegeneration. Transl. Neurodegener. 2012, 1, 24. [CrossRef]

50. Johnson, G.V.W. Tau phosphorylation in neuronal cell function and dysfunction. J. Cell Sci. 2004, 117, 5721-5729. [CrossRef]

51. Cabezas-Opazo, F.A.; Vergara-Pulgar, K.; Pérez, M.J.; Jara, C.; Osorio-Fuentealba, C.; Quintanilla, R.A. Mitochondrial Dysfunction Contributes to the Pathogenesis of Alzheimer's Disease. Oxidative Med. Cell Longev. 2015, 2015, 509654. [CrossRef]

52. Duncan, J.E.; Goldstein, L.S.B. The genetics of axonal transport and axonal transport disorders. PLoS Genet. 2006, 2, e124. [CrossRef]

53. Dixit, R.; Ross, J.L.; Goldman, Y.E.; Holzbaur, E.L.F. Differential regulation of dynein and kinesin motor proteins by tau. Science (N.Y.) 2008, 319, 1086-1089. [CrossRef]

54. Magnani, E.; Fan, J.; Gasparini, L.; Golding, M.; Williams, M.; Schiavo, G.; Goedert, M.; Amos, L.A.; Spillantini, M.G. Interaction of tau protein with the dynactin complex. Embo. J. 2007, 26, 4546-4554. [CrossRef]

55. Pooler, A.M.; Noble, W.; Hanger, D.P. A role for tau at the synapse in Alzheimer's disease pathogenesis. Neuropharmacology 2014, 76, 1-8. [CrossRef]

56. Fulga, T.A.; Elson-Schwab, I.; Khurana, V.; Steinhilb, M.L.; Spires, T.L.; Hyman, B.T.; Feany, M.B. Abnormal bundling and accumulation of F-actin mediates tau-induced neuronal degeneration in vivo. Nat. Cell Biol. 2007, 9, 139-148. [CrossRef]

57. Ittner, A.; Ittner, L.M. Dendritic Tau in Alzheimer's Disease. Neuron 2018, 99, 13-27. [CrossRef]

58. Ittner, L.M.; Ke, Y.D.; Delerue, F.; Bi, M.; Gladbach, A.; van Eersel, J.; Wolfing, H.; Chieng, B.C.; Christie, M.J.; Napier, I.A.; et al. Dendritic function of tau mediates amyloid-beta toxicity in Alzheimer's disease mouse models. Cell 2010, 142, 387-397. [CrossRef]

59. Lau, D.H.; Hogseth, M.; Phillips, E.C.; O’Neill, M.J.; Pooler, A.M.; Noble, W.; Hanger, D.P. Critical residues involved in tau binding to fyn: Implications for tau phosphorylation in Alzheimer's disease. Acta Neuropathol. Commun. 2016, 4, 49. [CrossRef]

60. Kimura, T.; Whitcomb, D.J.; Jo, J.; Regan, P.; Piers, T.; Heo, S.; Brown, C.; Hashikawa, T.; Murayama, M.; Seok, H.; et al. Microtubule-associated protein tau is essential for long-term depression in the hippocampus. Philos Trans. R. Soc. Lond B Biol. Sci. 2014, 369, 20130144. [CrossRef]

61. Nabavi, S.; Fox, R.; Proulx, C.D.; Lin, J.Y.; Tsien, R.Y.; Malinow, R. Engineering a memory with LTD and LTP. Nature 2014, 511, 348-352. [CrossRef]

62. Sultan, A.; Nesslany, F.; Violet, M.; Bégard, S.; Loyens, A.; Talahari, S.; Mansuroglu, Z.; Marzin, D.; Sergeant, N.; Humez, S.; et al. Nuclear tau, a key player in neuronal DNA protection. J. Biol. Chem. 2011, 286, 4566-4575. [CrossRef] [PubMed]

63. Violet, M.; Delattre, L.; Tardivel, M.; Sultan, A.; Chauderlier, A.; Caillierez, R.; Talahari, S.; Nesslany, F.; Lefebvre, B.; Bonnefoy, E.; et al. A major role for Tau in neuronal DNA and RNA protection in vivo under physiological and hyperthermic conditions. Front. Cell Neurosci. 2014, 8, 84. [CrossRef] [PubMed]

64. Sola, M.; Magrin, C.; Pedrioli, G.; Pinton, S.; Salvadè, A.; Papin, S.; Paganetti, P. Tau affects P53 function and cell fate during the DNA damage response. Commun. Biol. 2020, 3. [CrossRef] [PubMed] 
65. Grundke-Iqbal, I.; Iqbal, K.; Tung, Y.C.; Quinlan, M.; Wisniewski, H.M.; Binder, L.I. Abnormal phosphorylation of the microtubule-associated protein tau (tau) in Alzheimer cytoskeletal pathology. Proc. Natl. Acad. Sci. USA 1986, 83, 4913-4917. [CrossRef] [PubMed]

66. Ma, R.H.; Zhang, Y.; Hong, X.Y.; Zhang, J.F.; Wang, J.Z.; Liu, G.P. Role of microtubule-associated protein tau phosphorylation in Alzheimer's disease. J. Huazhong Univ. Sci. Technol. Med. Sci. 2017, 37, 307-312. [CrossRef] [PubMed]

67. Alonso, A.D.; Cohen, L.S.; Corbo, C.; Morozova, V.; ElIdrissi, A.; Phillips, G.; Kleiman, F.E. Hyperphosphorylation of Tau Associates With Changes in Its Function Beyond Microtubule Stability. Front. Cell Neurosci. 2018, 12. [CrossRef]

68. Sebastián-Serrano, Á.; de Diego-García, L.; Díaz-Hernández, M. The Neurotoxic Role of Extracellular Tau Protein. Int. J. Mol. Sci. 2018, 19, 998. [CrossRef]

69. Ackmann, M.; Wiech, H.; Mandelkow, E. Nonsaturable Binding Indicates Clustering of Tau on the Microtubule Surface in a Paired Helical Filament-like Conformation. J. Biol. Chem. 2000, 275, 30335-30343. [CrossRef]

70. Barbier, P.; Zejneli, O.; Martinho, M.; Lasorsa, A.; Belle, V.; Smet-Nocca, C.; Tsvetkov, P.O.; Devred, F.; Landrieu, I. Role of Tau as a Microtubule-Associated Protein: Structural and Functional Aspects. Front. Aging Neurosci. 2019, 11. [CrossRef]

71. Sengupta, A.; Kabat, J.; Novak, M.; Wu, Q.; Grundke-Iqbal, I.; Iqbal, K. Phosphorylation of Tau at Both Thr 231 and Ser 262 Is Required for Maximal Inhibition of Its Binding to Microtubules. Arch. Biochem. Biophys. 1998, 357, 299-309. [CrossRef]

72. Wegmann, S.; Eftekharzadeh, B.; Tepper, K.; Zoltowska, K.M.; Bennett, R.E.; Dujardin, S.; Laskowski, P.R.; MacKenzie, D.; Kamath, T.; Commins, C.; et al. Tau protein liquid-liquid phase separation can initiate tau aggregation. Embo. J. 2018, 37, e98049. [CrossRef]

73. Fitzpatrick, A.W.P.; Falcon, B.; He, S.; Murzin, A.G.; Murshudov, G.; Garringer, H.J.; Crowther, R.A.; Ghetti, B.; Goedert, M.; Scheres, S.H.W. Cryo-EM structures of tau filaments from Alzheimer's disease. Nature 2017, 547, 185-190. [CrossRef]

74. Roy, S.; Zhang, B.; Lee, V.M.; Trojanowski, J.Q. Axonal transport defects: A common theme in neurodegenerative diseases. Acta Neuropathol. 2005, 109, 5-13. [CrossRef] [PubMed]

75. Chang, H.-Y.; Sang, T.-K.; Chiang, A.-S. Untangling the Tauopathy for Alzheimer's disease and parkinsonism. J. Biomed. Sci. 2018, 25, 54. [CrossRef] [PubMed]

76. Goedert, M. The ordered assembly of tau is the gain-of-toxic function that causes human tauopathies. Alzheimers Dement. 2016, 12, 1040-1050. [CrossRef] [PubMed]

77. Chu, D.; Liu, F. Pathological Changes of Tau Related to Alzheimer's Disease. Acs. Chem. Neurosci. 2019, 10, 931-944. [CrossRef]

78. Tracy, T.E.; Gan, L. Tau-mediated synaptic and neuronal dysfunction in neurodegenerative disease. Curr. Opin. Neurobiol. 2018, 51, 134-138. [CrossRef]

79. Medina, M.; Hernández, F.; Avila, J. New Features about Tau Function and Dysfunction. Biomolecules 2016, 6, 21. [CrossRef]

80. Cowan, C.; Mudher, A. Are Tau Aggregates Toxic or Protective in Tauopathies? Front. Neurol. $2013,4$. [CrossRef]

81. Vogels, T.; Murgoci, A.-N.; Hromádka, T. Intersection of pathological tau and microglia at the synapse. Acta Neuropathol. Commun. 2019, 7. [CrossRef]

82. Maphis, N.; Xu, G.; Kokiko-Cochran, O.N.; Jiang, S.; Cardona, A.; Ransohoff, R.M.; Lamb, B.T.; Bhaskar, K. Reactive microglia drive tau pathology and contribute to the spreading of pathological tau in the brain. Brain 2015, 138, 1738-1755. [CrossRef] [PubMed]

83. Jadhav, S.; Avila, J.; Schöll, M.; Kovacs, G.G.; Kövari, E.; Skrabana, R.; Evans, L.D.; Kontsekova, E.; Malawska, B.; de Silva, R.; et al. A walk through tau therapeutic strategies. Acta Neuropathol. Commun. 2019, 7. [CrossRef] [PubMed]

84. Lou, G.; Palikaras, K.; Lautrup, S.; Scheibye-Knudsen, M.; Tavernarakis, N.; Fang, E.F. Mitophagy and Neuroprotection. Trends Mol. Med. 2020, 26, 8-20. [CrossRef] [PubMed]

85. Hou, Y.; Lautrup, S.; Cordonnier, S.; Wang, Y.; Croteau, D.L.; Zavala, E.; Zhang, Y.; Moritoh, K.; O'Connell, J.F.; Baptiste, B.A.; et al. NAD+ supplementation normalizes key Alzheimer's features and DNA damage responses in a new AD mouse model with introduced DNA repair deficiency. Proc. Natl. Acad. Sci. USA 2018, 115, E1876-E1885. [CrossRef] [PubMed] 
86. Fang, E.F.; Hou, Y.; Palikaras, K.; Adriaanse, B.A.; Kerr, J.S.; Yang, B.; Lautrup, S.; Hasan-Olive, M.M.; Caponio, D.; Dan, X.; et al. Mitophagy inhibits amyloid- $\beta$ and tau pathology and reverses cognitive deficits in models of Alzheimer's disease. Nat. Neurosci. 2019, 22, 401-412. [CrossRef]

87. Wilkins, H.M.; Swerdlow, R.H. Relationships Between Mitochondria and Neuroinflammation: Implications for Alzheimer's Disease. Curr. Top. Med. Chem. 2016, 16, 849-857. [CrossRef]

88. Oz, M.; Lorke, D.E.; Petroianu, G.A. Methylene blue and Alzheimer's disease. Biochem. Pharmacol. 2009, 78, 927-932. [CrossRef]

89. Luo, S.; Valencia, C.A.; Zhang, J.; Lee, N.-C.; Slone, J.; Gui, B.; Wang, X.; Li, Z.; Dell, S.; Brown, J.; et al. Biparental Inheritance of Mitochondrial DNA in Humans. Proc. Natl. Acad. Sci. USA 2018, 115, 13039-13044. [CrossRef]

90. Rius, R.; Cowley, M.J.; Riley, L.; Puttick, C.; Thorburn, D.R.; Christodoulou, J. Biparental inheritance of mitochondrial DNA in humans is not a common phenomenon. Genet. Med. 2019, 21, 2823-2826. [CrossRef]

91. Tilokani, L.; Nagashima, S.; Paupe, V.; Prudent, J. Mitochondrial dynamics: Overview of molecular mechanisms. Essays Biochem. 2018, 62, 341-360. [CrossRef]

92. Vakifahmetoglu-Norberg, H.; Ouchida, A.T.; Norberg, E. The role of mitochondria in metabolism and cell death. Biochem. Biophys. Res. Commun. 2017, 482, 426-431. [CrossRef]

93. Caito, S.W.; Aschner, M. Mitochondrial Redox Dysfunction and Environmental Exposures. Antioxid. Redox Signal. 2015, 23, 578-595. [CrossRef] [PubMed]

94. van der Bliek, A.M.; Sedensky, M.M.; Morgan, P.G. Cell Biology of the Mitochondrion. Genetics 2017, 207, 843-871. [CrossRef] [PubMed]

95. Roy Chowdhury, S.; Banerji, V. Targeting Mitochondrial Bioenergetics as a Therapeutic Strategy for Chronic Lymphocytic Leukemia. Oxid. Med. Cell Longev. 2018, 2018, 2426712. [CrossRef] [PubMed]

96. Letts, J.A.; Sazanov, L.A. Clarifying the supercomplex: The higher-order organization of the mitochondrial electron transport chain. Nat. Struct. Mol. Biol. 2017, 24, 800-808. [CrossRef] [PubMed]

97. Lejri, I.; Agapouda, A.; Grimm, A.; Eckert, A. Mitochondria- and Oxidative Stress-Targeting Substances in Cognitive Decline-Related Disorders: From Molecular Mechanisms to Clinical Evidence. Oxidative Med. Cell Longev. 2019, 2019, 9695412. [CrossRef]

98. Grimm, A.; Friedland, K.; Eckert, A. Mitochondrial dysfunction: The missing link between aging and sporadic Alzheimer's disease. Biogerontology 2016, 17, 281-296. [CrossRef]

99. Grimm, A.; Mensah-Nyagan, A.G.; Eckert, A. Alzheimer, mitochondria and gender. Neurosci. Biobehav. Rev. 2016, 67, 89-101. [CrossRef]

100. Swerdlow, R.H.; Burns, J.M.; Khan, S.M. The Alzheimer's disease mitochondrial cascade hypothesis: Progress and perspectives. Biochim. Biophys. Acta 2014, 1842, 1219-1231. [CrossRef]

101. Leuner, K.; Schutt, T.; Kurz, C.; Eckert, S.H.; Schiller, C.; Occhipinti, A.; Mai, S.; Jendrach, M.; Eckert, G.P.; Kruse, S.E.; et al. Mitochondrion-derived reactive oxygen species lead to enhanced amyloid beta formation. Antioxid. Redox Signal. 2012, 16, 1421-1433. [CrossRef]

102. Khoury, J.E.; Melov, S.; Adlard, P.A.; Morten, K.; Johnson, F.; Golden, T.R.; Hinerfeld, D.; Schilling, B.; Mavros, C.; Masters, C.L.; et al. Mitochondrial Oxidative Stress Causes Hyperphosphorylation of Tau. PLoS ONE 2007, 2, e536. [CrossRef]

103. Lee, H.; Yoon, Y. Mitochondrial fission and fusion. Biochem. Soc. Trans. 2016, 44, 1725-1735. [CrossRef] [PubMed]

104. Meyer, J.N.; Leuthner, T.C.; Luz, A.L. Mitochondrial fusion, fission, and mitochondrial toxicity. Toxicology 2017, 391, 42-53. [CrossRef] [PubMed]

105. Joshi, A.U.; Mochly-Rosen, D. Mortal engines: Mitochondrial bioenergetics and dysfunction in neurodegenerative diseases. Pharm. Res. 2018, 138, 2-15. [CrossRef] [PubMed]

106. Eckert, A.; Nisbet, R.; Grimm, A.; Götz, J. March separate, strike together-role of phosphorylated TAU in mitochondrial dysfunction in Alzheimer's disease. Biochim. Biophys. Acta 2014, 1842, 1258-1266. [CrossRef]

107. Giacomello, M.; Pyakurel, A.; Glytsou, C.; Scorrano, L. The cell biology of mitochondrial membrane dynamics. Nat. Rev. Mol. Cell Biol. 2020, 21, 204-224. [CrossRef]

108. Scott, I.; Youle, R.J. Mitochondrial fission and fusion. Essays Biochem. 2010, 47, 85-98. [CrossRef]

109. Bertholet, A.M.; Delerue, T.; Millet, A.M.; Moulis, M.F.; David, C.; Daloyau, M.; Arnauné-Pelloquin, L.; Davezac, N.; Mils, V.; Miquel, M.C.; et al. Mitochondrial fusion/fission dynamics in neurodegeneration and neuronal plasticity. Neurobiol. Dis. 2016, 90, 3-19. [CrossRef] 
110. Wang, X.; Su, B.; Lee, H.-g.; Li, X.; Perry, G.; Smith, M.A.; Zhu, X. Impaired balance of mitochondrial fission and fusion in Alzheimer's disease. J. Neurosci. 2009, 29, 9090-9103. [CrossRef]

111. Manczak, M.; Calkins, M.J.; Reddy, P.H. Impaired mitochondrial dynamics and abnormal interaction of amyloid beta with mitochondrial protein Drp1 in neurons from patients with Alzheimer's disease: Implications for neuronal damage. Hum. Mol. Genet. 2011, 20, 2495-2509. [CrossRef]

112. Flannery, P.J.; Trushina, E. Mitochondrial dynamics and transport in Alzheimer's disease. Mol. Cell Neurosci. 2019, 98, 109-120. [CrossRef] [PubMed]

113. Mishra, P.; Chan, D.C. Metabolic regulation of mitochondrial dynamics. J. Cell Biol. 2016, 212, 379-387. [CrossRef] [PubMed]

114. Chen, H.; Chan, D.C. Mitochondrial dynamics-fusion, fission, movement, and mitophagy-in neurodegenerative diseases. Hum. Mol. Genet. 2009, 18, R169-R176. [CrossRef] [PubMed]

115. Palikaras, K.; Tavernarakis, N. Mitochondrial homeostasis: The interplay between mitophagy and mitochondrial biogenesis. Exp. Gerontol. 2014, 56, 182-188. [CrossRef] [PubMed]

116. Melser, S.; Lavie, J.; Bénard, G. Mitochondrial degradation and energy metabolism. Biochim. Biophys. Acta 2015, 1853, 2812-2821. [CrossRef] [PubMed]

117. Cummins, N.; Tweedie, A.; Zuryn, S.; Bertran-Gonzalez, J.; Götz, J. Disease-associated tau impairs mitophagy by inhibiting Parkin translocation to mitochondria. Embo. J. 2018, 38. [CrossRef]

118. Kerr, J.S.; Adriaanse, B.A.; Greig, N.H.; Mattson, M.P.; Cader, M.Z.; Bohr, V.A.; Fang, E.F. Mitophagy and Alzheimer's Disease: Cellular and Molecular Mechanisms. Trends Neurosci. 2017, 40, 151-166. [CrossRef]

119. Ittner, L.M.; Fath, T.; Ke, Y.D.; Bi, M.; van Eersel, J.; Li, K.M.; Gunning, P.; Gotz, J. Parkinsonism and impaired axonal transport in a mouse model of frontotemporal dementia. Proc. Natl. Acad. Sci. USA 2008, 105, 15997-16002. [CrossRef]

120. Kopeikina, K.J.; Carlson, G.A.; Pitstick, R.; Ludvigson, A.E.; Peters, A.; Luebke, J.I.; Koffie, R.M.; Frosch, M.P.; Hyman, B.T.; Spires-Jones, T.L. Tau Accumulation Causes Mitochondrial Distribution Deficits in Neurons in a Mouse Model of Tauopathy and in Human Alzheimer's Disease Brain. Am. J. Pathol. 2011, 179, 2071-2082. [CrossRef]

121. Shahpasand, K.; Uemura, I.; Saito, T.; Asano, T.; Hata, K.; Shibata, K.; Toyoshima, Y.; Hasegawa, M.; Hisanaga, S.i. Regulation of Mitochondrial Transport and Inter-Microtubule Spacing by Tau Phosphorylation at the Sites Hyperphosphorylated in Alzheimer's Disease. J. Neurosci. 2012, 32, 2430-2441. [CrossRef]

122. Rodríguez-Martín, T.; Pooler, A.M.; Lau, D.H.W.; Mórotz, G.M.; De Vos, K.J.; Gilley, J.; Coleman, M.P.; Hanger, D.P. Reduced number of axonal mitochondria and tau hypophosphorylation in mouse P301L tau knockin neurons. Neurobiol. Dis. 2016, 85, 1-10. [CrossRef] [PubMed]

123. Iovino, M.; Agathou, S.; González-Rueda, A.; Del Castillo Velasco-Herrera, M.; Borroni, B.; Alberici, A.; Lynch, T.; O’Dowd, S.; Geti, I.; Gaffney, D.; et al. Early maturation and distinct tau pathology in induced pluripotent stem cell-derived neurons from patients withMAPTmutations. Brain 2015, 138, 3345-3359. [CrossRef] [PubMed]

124. Nakamura, M.; Shiozawa, S.; Tsuboi, D.; Amano, M.; Watanabe, H.; Maeda, S.; Kimura, T.; Yoshimatsu, S.; Kisa, F.; Karch, C.M.; et al. Pathological Progression Induced by the Frontotemporal Dementia-Associated R406W Tau Mutation in Patient-Derived iPSCs. Stem Cell Rep. 2019, 13, 684-699. [CrossRef] [PubMed]

125. DuBoff, B.; Gotz, J.; Feany, M.B. Tau promotes neurodegeneration via DRP1 mislocalization in vivo. Neuron 2012, 75, 618-632. [CrossRef] [PubMed]

126. Li, X.-C.; Hu, Y.; Wang, Z.-h.; Luo, Y.; Zhang, Y.; Liu, X.-P.; Feng, Q.; Wang, Q.; Ye, K.; Liu, G.-P.; et al. Human wild-type full-length tau accumulation disrupts mitochondrial dynamics and the functions via increasing mitofusins. Sci. Rep. 2016, 6. [CrossRef]

127. Schulz, K.L.; Eckert, A.; Rhein, V.; Mai, S.; Haase, W.; Reichert, A.S.; Jendrach, M.; Muller, W.E.; Leuner, K. A new link to mitochondrial impairment in tauopathies. Mol. Neurobiol. 2012, 46, 205-216. [CrossRef]

128. David, D.C.; Hauptmann, S.; Scherping, I.; Schuessel, K.; Keil, U.; Rizzu, P.; Ravid, R.; Drose, S.; Brandt, U.; Muller, W.E.; et al. Proteomic and functional analyses reveal a mitochondrial dysfunction in P301L tau transgenic mice. J. Biol. Chem. 2005, 280, 23802-23814. [CrossRef]

129. Rhein, V.; Song, X.; Wiesner, A.; Ittner, L.M.; Baysang, G.; Meier, F.; Ozmen, L.; Bluethmann, H.; Drose, S.; Brandt, U.; et al. Amyloid-beta and tau synergistically impair the oxidative phosphorylation system in triple transgenic Alzheimer's disease mice. Proc. Natl. Acad. Sci. USA 2009, 106, 20057-20062. [CrossRef] 
130. Grimm, A.; Biliouris, E.E.; Lang, U.E.; Götz, J.; Mensah-Nyagan, A.G.; Eckert, A. Sex hormone-related neurosteroids differentially rescue bioenergetic deficits induced by amyloid-beta or hyperphosphorylated tau protein. Cell. Mol. Life Sci. CMLS 2016, 73, 201-215. [CrossRef]

131. Grimm, A.; Lejri, I.; Hallé, F.; Schmitt, M.; Götz, J.; Bihel, F.; Eckert, A. Mitochondria modulatory effects of new TSPO ligands in a cellular model of tauopathies. J. Neuroendocrinol. 2019. [CrossRef]

132. Jara, C.; Aránguiz, A.; Cerpa, W.; Tapia-Rojas, C.; Quintanilla, R.A. Genetic ablation of tau improves mitochondrial function and cognitive abilities in the hippocampus. Redox Biol. 2018, 18, 279-294. [CrossRef] [PubMed]

133. Hu, Y.; Li, X.-C.; Wang, Z.-h.; Luo, Y.; Zhang, X.; Liu, X.-P.; Feng, Q.; Wang, Q.; Yue, Z.; Chen, Z.; et al. Tau accumulation impairs mitophagy via increasing mitochondrial membrane potential and reducing mitochondrial Parkin. Oncotarget 2016, 7, 17356-17368. [CrossRef] [PubMed]

134. Ittner, L.M.; Ke, Y.D.; Götz, J. Phosphorylated Tau Interacts with c-Jun N-terminal Kinase-interacting Protein 1 (JIP1) in Alzheimer Disease. J. Biol. Chem. 2009, 284, 20909-20916. [CrossRef] [PubMed]

135. Alonso, A.C.; Zaidi, T.; Grundke-Iqbal, I.; Iqbal, K. Role of abnormally phosphorylated tau in the breakdown of microtubules in Alzheimer disease. Proc. Natl. Acad. Sci. USA 1994, 91, 5562-5566. [CrossRef]

136. Lee, M.K.; Iijima-Ando, K.; Sekiya, M.; Maruko-Otake, A.; Ohtake, Y.; Suzuki, E.; Lu, B.; Iijima, K.M. Loss of Axonal Mitochondria Promotes Tau-Mediated Neurodegeneration and Alzheimer's Disease-Related Tau Phosphorylation Via PAR-1. PLoS Genet. 2012, 8, e1002918. [CrossRef]

137. Polleux, F.; Bardai, F.H.; Ordonez, D.G.; Bailey, R.M.; Hamm, M.; Lewis, J.; Feany, M.B. Lrrk promotes tau neurotoxicity through dysregulation of actin and mitochondrial dynamics. PLoS Biol. 2018, 16, e2006265. [CrossRef]

138. Zheng, J.; Akbari, M.; Schirmer, C.; Reynaert, M.-L.; Loyens, A.; Lefebvre, B.; Buée, L.; Croteau, D.L.; Galas, M.-C.; Bohr, V.A. Hippocampal tau oligomerization early in tau pathology coincides with a transient alteration of mitochondrial homeostasis and DNA repair in a mouse model of tauopathy. Acta Neuropathol. Commun. 2020, 8. [CrossRef]

139. Pérez, M.J.; Vergara-Pulgar, K.; Jara, C.; Cabezas-Opazo, F.; Quintanilla, R.A. Caspase-Cleaved Tau Impairs Mitochondrial Dynamics in Alzheimer's Disease. Mol. Neurobiol. 2017, 55, 1004-1018. [CrossRef]

140. Delic, V.; Brownlow, M.; Joly-Amado, A.; Zivkovic, S.; Noble, K.; Phan, T.-A.; Ta, Y.; Zhang, Y.; Bell, S.D.; Kurien, C.; et al. Calorie restriction does not restore brain mitochondrial function in P301L tau mice, but it does decrease mitochondrial F0F1-ATPase activity. Mol. Cell. Neurosci. 2015, 67, 46-54. [CrossRef]

141. Esteras, N.; Rohrer, J.D.; Hardy, J.; Wray, S.; Abramov, A.Y. Mitochondrial hyperpolarization in iPSC-derived neurons from patients of FTDP-17 with 10+16 MAPT mutation leads to oxidative stress and neurodegeneration. Redox Biol. 2017, 12, 410-422. [CrossRef]

142. Camilleri, A.; Ghio, S.; Caruana, M.; Weckbecker, D.; Schmidt, F.; Kamp, F.; Leonov, A.; Ryazanov, S.; Griesinger, C.; Giese, A.; et al. Tau-induced mitochondrial membrane perturbation is dependent upon cardiolipin. Biochim. Biophys. Acta (Bba) Biomembr. 2020, 1862, 183064. [CrossRef] [PubMed]

143. Kalani, K.; Yan, S.F.; Yan, S.S. Mitochondrial permeability transition pore: A potential drug target for neurodegeneration. Drug Discov. Today 2018, 23, 1983-1989. [CrossRef] [PubMed]

144. Liu, C.; Song, X.; Nisbet, R.; Götz, J. Co-immunoprecipitation with Tau Isoform-specific Antibodies Reveals Distinct Protein Interactions and Highlights a Putative Role for 2N Tau in Disease. J. Biol. Chem. 2016, 291, 8173-8188. [CrossRef] [PubMed]

145. Manczak, M.; Reddy, P.H. Abnormal interaction of VDAC1 with amyloid beta and phosphorylated tau causes mitochondrial dysfunction in Alzheimer's disease. Hum. Mol. Genet. 2012, 21, 5131-5146. [CrossRef]

146. Amadoro, G.; Corsetti, V.; Florenzano, F.; Atlante, A.; Ciotti, M.T.; Mongiardi, M.P.; Bussani, R.; Nicolin, V.; Nori, S.L.; Campanella, M.; et al. AD-linked, toxic NH2 human tau affects the quality control of mitochondria in neurons. Neurobiol. Dis. 2014, 62, 489-507. [CrossRef]

147. Corsetti, V.; Florenzano, F.; Atlante, A.; Bobba, A.; Ciotti, M.T.; Natale, F.; Della Valle, F.; Borreca, A.; Manca, A.; Meli, G.; et al. NH2-truncated human tau induces deregulated mitophagy in neurons by aberrant recruitment of Parkin and UCHL-1: Implications in Alzheimer's disease. Hum. Mol. Genet. 2015, 24, 3058-3081. [CrossRef]

148. Porcu, P.; Barron, A.M.; Frye, C.A.; Walf, A.A.; Yang, S.Y.; He, X.Y.; Morrow, A.L.; Panzica, G.C.; Melcangi, R.C. Neurosteroidogenesis Today: Novel Targets for Neuroactive Steroid Synthesis and Action and Their Relevance for Translational Research. J. Neuroendocrinol. 2016, 28. [CrossRef] 
149. Reddy, D.S.; Estes, W.A. Clinical Potential of Neurosteroids for CNS Disorders. Trends Pharmacol. Sci. 2016, 37, 543-561. [CrossRef]

150. Weill-Engerer, S.b.; David, J.-P.; Sazdovitch, V.r.; Liere, P.; Eychenne, B.; Pianos, A.; Schumacher, M.; Delacourte, A.; Baulieu, E.-E.; Akwa, Y. Neurosteroid Quantification in Human Brain Regions: Comparison between Alzheimer's and Nondemented Patients. J. Clin. Endocrinol. Metab. 2002, 87, 5138-5143. [CrossRef]

151. Marx, C.E.; Trost, W.T.; Shampine, L.J.; Stevens, R.D.; Hulette, C.M.; Steffens, D.C.; Ervin, J.F.; Butterfield, M.I.; Blazer, D.G.; Massing, M.W.; et al. The Neurosteroid Allopregnanolone Is Reduced in Prefrontal Cortex in Alzheimer's Disease. Biol. Psychiatry 2006, 60, 1287-1294. [CrossRef]

152. Akwa, Y. Steroids and Alzheimer's Disease: Changes Associated with Pathology and Therapeutic Potential. Int. J. Mol. Sci. 2020, 21, 4812. [CrossRef] [PubMed]

153. Grimm, A.; Schmitt, K.; Lang, U.E.; Mensah-Nyagan, A.G.; Eckert, A. Improvement of neuronal bioenergetics by neurosteroids: Implications for age-related neurodegenerative disorders. Biochim. Et Biophys. Acta 2014, 1842, 2427-2438. [CrossRef] [PubMed]

154. Lejri, I.; Grimm, A.; Miesch, M.; Geoffroy, P.; Eckert, A.; Mensah-Nyagan, A.G. Allopregnanolone and its analog BR 297 rescue neuronal cells from oxidative stress-induced death through bioenergetic improvement. Biochim. Biophys. Acta 2017, 1863, 631-642. [CrossRef] [PubMed]

155. Brinton, R.D. Neurosteroids as regenerative agents in the brain: Therapeutic implications. Nat. Rev. Endocrinol. 2013, 9, 241-250. [CrossRef]

156. Irwin, R.W.; Brinton, R.D. Allopregnanolone as regenerative therapeutic for Alzheimer's disease: Translational development and clinical promise. Prog. Neurobiol. 2014, 113, 40-55. [CrossRef]

157. Wang, T.; Yao, J.; Chen, S.; Mao, Z.; Brinton, R.D. Allopregnanolone Reverses Bioenergetic Deficits in Female Triple Transgenic Alzheimer's Mouse Model. Neurotherapeutics 2019, 17, 178-188. [CrossRef]

158. Minami, M.; Chen, S.; Wang, J.M.; Irwin, R.W.; Yao, J.; Liu, L.; Brinton, R.D. Allopregnanolone Promotes Regeneration and Reduces $\beta$-Amyloid Burden in a Preclinical Model of Alzheimer's Disease. PLoS ONE 2011, 6, e24293. [CrossRef]

159. Brinton, R.D.; Schneider, L.S.; Law, M. Allopregnanolone, Regenerative Therapeutic for Alzheimer's Disease: Phase 1b/2a Update. Alzheimer's Dement. 2017, 13, P939-P940. [CrossRef]

160. Area-Gomez, E.; Schon, E.A. Mitochondria-associated ER membranes and Alzheimer disease. Curr. Opin. Genet. Dev. 2016, 38, 90-96. [CrossRef]

161. Paillusson, S.; Stoica, R.; Gomez-Suaga, P.; Lau, D.H.W.; Mueller, S.; Miller, T.; Miller, C.C.J. There's Something Wrong with my MAM; the ER-Mitochondria Axis and Neurodegenerative Diseases. Trends Neurosci. 2016, 39, 146-157. [CrossRef]

162. Volgyi, K.; Juhász, G.; Kovacs, Z.; Penke, B. Dysfunction of Endoplasmic Reticulum (ER) and Mitochondria (MT) in Alzheimer's Disease: The Role of the ER-MT Cross-Talk. Curr. Alzheimer Res. 2015, 12, 655-672. [CrossRef] [PubMed]

163. Missiroli, S.; Patergnani, S.; Caroccia, N.; Pedriali, G.; Perrone, M.; Previati, M.; Wieckowski, M.R.; Giorgi, C. Mitochondria-associated membranes (MAMs) and inflammation. Cell Death Dis. 2018, 9, 329. [CrossRef] [PubMed]

164. Erpapazoglou, Z.; Mouton-Liger, F.; Corti, O. From dysfunctional endoplasmic reticulum-mitochondria coupling to neurodegeneration. Neurochem. Int. 2017, 109, 171-183. [CrossRef] [PubMed]

165. Hedskog, L.; Pinho, C.M.; Filadi, R.; Ronnback, A.; Hertwig, L.; Wiehager, B.; Larssen, P.; Gellhaar, S.; Sandebring, A.; Westerlund, M.; et al. Modulation of the endoplasmic reticulum-mitochondria interface in Alzheimer's disease and related models. Proc. Natl. Acad. Sci. USA 2013, 110, 7916-7921. [CrossRef] [PubMed]

166. Area-Gomez, E.; Del Carmen Lara Castillo, M.; Tambini, M.D.; Guardia-Laguarta, C.; de Groof, A.J.; Madra, M.; Ikenouchi, J.; Umeda, M.; Bird, T.D.; Sturley, S.L.; et al. Upregulated function of mitochondria-associated ER membranes in Alzheimer disease. Embo. J. 2012, 31, 4106-4123. [CrossRef]

167. Schon, E.A.; Area-Gomez, E. Mitochondria-associated ER membranes in Alzheimer disease. Mol. Cell Neurosci. 2013, 55, 26-36. [CrossRef]

168. Stoica, R.; De Vos, K.J.; Paillusson, S.; Mueller, S.; Sancho, R.M.; Lau, K.-F.; Vizcay-Barrena, G.; Lin, W.-L.; $\mathrm{Xu}$, Y.-F.; Lewis, J.; et al. ER-mitochondria associations are regulated by the VAPB-PTPIP51 interaction and are disrupted by ALS/FTD-associated TDP-43. Nat. Commun. 2014, 5. [CrossRef] 
169. Le Masson, G.; Przedborski, S.; Abbott, L.F. A Computational Model of Motor Neuron Degeneration. Neuron 2014, 83, 975-988. [CrossRef]

170. Perreault, S.; Bousquet, O.; Lauzon, M.; Paiement, J.; Leclerc, N. Increased association between rough endoplasmic reticulum membranes and mitochondria in transgenic mice that express P301L tau. J. Neuropathol. Exp. Neurol. 2009, 68, 503-514. [CrossRef]

171. Cieri, D.; Vicario, M.; Vallese, F.; D’Orsi, B.; Berto, P.; Grinzato, A.; Catoni, C.; De Stefani, D.; Rizzuto, R.; Brini, M.; et al. Tau localises within mitochondrial sub-compartments and its caspase cleavage affects ER-mitochondria interactions and cellular Ca2+ handling. Biochim. Et Biophys. Acta (Bba) Mol. Basis Dis. 2018, 1864, 3247-3256. [CrossRef]

172. Poirier, Y.; Grimm, A.; Schmitt, K.; Eckert, A. Link between the unfolded protein response and dysregulation of mitochondrial bioenergetics in Alzheimer's disease. Cell. Mol. Life Sci. 2019, 76, 1419-1431. [CrossRef] [PubMed]

173. Griebel, G.; Stemmelin, J.; Lopez-Grancha, M.; Boulay, D.; Boquet, G.; Slowinski, F.; Pichat, P.; Beeské, S.; Tanaka, S.; Mori, A.; et al. The selective GSK3 inhibitor, SAR502250, displays neuroprotective activity and attenuates behavioral impairments in models of neuropsychiatric symptoms of Alzheimer's disease in rodents. Sci. Rep. 2019, 9. [CrossRef] [PubMed]

174. Ochalek, A.; Mihalik, B.; Avci, H.X.; Chandrasekaran, A.; Téglási, A.; Bock, I.; Giudice, M.L.; Táncos, Z.; Molnár, K.; László, L.; et al. Neurons derived from sporadic Alzheimer's disease iPSCs reveal elevated TAU hyperphosphorylation, increased amyloid levels, and GSK3B activation. Alzheimer's Res. Ther. 2017, 9. [CrossRef] [PubMed]

(C) 2020 by the authors. Licensee MDPI, Basel, Switzerland. This article is an open access article distributed under the terms and conditions of the Creative Commons Attribution (CC BY) license (http://creativecommons.org/licenses/by/4.0/). 